\title{
Investigating benthic impacts at salmon farms using eddy covariance measurements of benthic oxygen fluxes
}

\author{
David R. Plew* \\ National Institute of Water and Atmospheric Research, PO Box 8602, Christchurch 8440, New Zealand
}

\begin{abstract}
Benthic oxygen fluxes were measured in situ using the eddy covariance method at 2 Chinook salmon farms located in the New Zealand Marlborough Sounds in 29-35 m depth and compared to sediment nutrient ( $\mathrm{C}, \mathrm{N}$ and $\mathrm{P}$ ) and sulphide concentrations. Observations from 3 sites at a high-flow location (near-bed RMS velocities of 0.11 to $0.17 \mathrm{~m} \mathrm{~s}^{-1}$ ) showed oxygen fluxes increasing with sediment enrichment. Mean $\pm \mathrm{SE}$ oxygen fluxes of $-102 \pm 4 \mathrm{mmol} \mathrm{O}_{2} \mathrm{~m}^{-2} \mathrm{~d}^{-1}$ were observed immediately adjacent the farm. Higher fluxes were observed at $120 \mathrm{~m}$ from the farm $\left(-53 \mathrm{mmol} \mathrm{O}_{2} \mathrm{~m}^{-2} \mathrm{~d}^{-1}\right)$ than at $50 \mathrm{~m}\left(-48 \mathrm{mmol} \mathrm{O}_{2} \mathrm{~m}^{-2} \mathrm{~d}^{-1}\right)$, consistent with higher sediment nutrient concentrations at the more distant site, and reflecting the effect of currents on deposition patterns. Ratios of $\mathrm{C}, \mathrm{N}$ and $\mathrm{P}$ in sediments indicated a reduction of $\mathrm{N}$ mineralisation rates as sediment enrichment increased. The low-flow site (near-bed RMS velocities of $0.033 \mathrm{~m} \mathrm{~s}^{-1}$ ) had similar oxygen fluxes $\left(-108 \pm 9 \mathrm{mmol} \mathrm{O}_{2} \mathrm{~m}^{-2} \mathrm{~d}^{-1}\right)$ to the high-flow site closest to the farm, but sediments were more highly enriched with high sulphide concentrations. Oxygen fluxes at the low-flow site were close to the estimated maximum potential flux that could be achieved under the ambient hydrodynamic conditions. Less than $0.2 \%$ of surface PAR reached the sediments, and no evidence of benthic primary production was observed at any of the sites. By incorporating ambient hydrodynamic conditions, eddy covariance has the potential to obtain true in situ benthic oxygen fluxes, giving greater insight into aquaculture-environmental interactions.
\end{abstract}

KEY WORDS: Aquaculture - Benthic impacts - Oxygen flux - Organic enrichment - Eddy covariance $\cdot$ Salmon

\section{INTRODUCTION}

Deposition of organic material beneath finfish farms is a major concern for the ecological health of the seabed (Brown et al. 1987, Hargrave et al. 1993, Findlay et al. 1995). Effects of this deposition include geo-chemical changes such as increased organic matter, organic $\mathrm{C}, \mathrm{N}$ and sulphides in sediments; decreased redox potential, increased oxygen uptake, and $\mathrm{CO}_{2}$ and ammonium release; as well as ecological changes including reduced macrofauna diversity and changes in abundance and community composition (Giles 2008 and references therein). Enriched wastes from finfish farms are remineralised, exported

*Corresponding author: david.plew@niwa.co.nz or accumulate (i.e. are buried) in the sediments. Remineralisation occurs through various mechanisms, many of which either directly or indirectly consume oxygen (Glud 2008). Aerobic respiration uses oxygen directly to oxidise $\mathrm{C}$, but oxygen is rapidly depleted and penetrates only small distances $(\mathrm{mm}$ or $\mathrm{cm}$ ) into sediments. Anaerobic processes use nitrate, manganese oxides, iron oxides or sulphate as electronic acceptors, but the reduced products are, to a large extent, re-oxidised by oxygen (Glud 2008). Consequently, benthic oxygen consumption rate has been used to measure the impact of decomposition of deposited organic matter (Findlay \& Watling 1997, Valdemarsen et al. 2012, Sweetman et al. 2014) and

(C) The author 2019. Open Access under Creative Commons by Attribution Licence. Use, distribution and reproduction are unrestricted. Authors and original publication must be credited. 
is a widely used proxy for quantifying mineralisation, re-oxidation of reduced compounds of marine sediments and primary production (Glud 2008).

Benthic oxygen consumption increases as sediments beneath finfish farms become enriched with $\mathrm{C}$ (Findlay \& Watling 1997, Nickell et al. 2003) and thus may be used as an indicator of enrichment (Cathalot et al. 2012). However, while the demand for oxygen increases with the concentration of organic matter in the sediments, the supply of oxygen is restricted by the rate it can be transported across the diffusive boundary layer either by diffusion or through turbulent bursting events (Hondzo 1998, Glud 2008, O'Connor \& Hondzo 2008, Grant \& Marusic 2011, Sulpis et al. 2019). The thickness of this layer, and hence potential rates of transport through this layer, depends on the nature and roughness of the substrate (Dade 1993, Røy et al. 2002), but also on the intensity of near-bed turbulence (Hondzo 1998, Lorke et al. 2003) and the action of bioturbation and bio-irrigation (Svensson \& Leonardson 1996, Pischedda et al. 2008). Consequently, assessing benthic impacts using benthic oxygen fluxes requires that measurements are conducted in such a way that captures the in situ hydrodynamic conditions and spatial heterogeneity.

Methods commonly used to quantify benthic oxygen consumption at aquaculture sites include laboratory incubation of sediment cores (e.g. Hargrave et al. 1993, Findlay \& Watling 1997, Christensen et al. 2000, Valdemarsen et al. 2012), in situ chambers (e.g. Hall et al. 1990, Findlay \& Watling 1997, Nickell et al. 2003, Cathalot et al. 2012, Valdemarsen et al. 2012) or measuring dissolved oxygen (DO) gradients with microelectrodes in the diffusive boundary layer and upper sediment layer either in situ (Cathalot et al. 2012) or on cores (Mulsow et al. 2006). However, these methods all have potentially significant limitations. Cores, chambers and microprofiles all sample small areas, and spatial variability in sediment conditions may result in unrepresentative flux measurements. Similarly, natural fauna density and behaviour (bioturbation and bio-irrigation) may not be well represented in enclosures or cores, and their contribution to fluxes cannot be easily obtained from microprofiles. Taking undisturbed sediment cores can also prove challenging. In addition, the use of chambers or cores means that measurements are made under different hydrodynamic conditions to those that occur naturally (Berg et al. 2003).

The eddy covariance (EC) technique has a number of advantages that make it potentially well-suited to aquaculture studies: it does not disturb the sediment, it provides high temporal resolution and retains the effects of hydrodynamic forcing, bioturbation and bio-irrigation (Kuwae et al. 2006, McGinnis et al. 2008, Attard et al. 2015). It also integrates fluxes over an area of typically 10-100 $\mathrm{m}^{2}$ (Berg et al. 2007), reducing the potential for measurements to be biased by local anomalies in sediment properties. Yet, to my knowledge, EC measurements of benthic oxygen uptake beneath an aquaculture site have not yet been published.

In principle, applying the EC technique at aquaculture sites should be relatively straightforward. Deployments can be made in moderate depths in sheltered waters, do not require the use of divers, and a strong signal of benthic oxygen uptake is expected due to high organic loadings. However, salmon farms can be located in strongly tidal flows. Large-scale flow structures such as eddy shedding from headlands or flow disturbance from farm structures and the small length-scales of the farm relative to the tidal excursion may result in strong transients in flows and oxygen which can influence flux measurements (Holtappels et al. 2013). These make it difficult to separate the flux transporting timescales from the meso-scale transients (McGinnis et al. 2008, Lorrai et al. 2010, Holtappels et al. 2013). The water column around aquaculture sites can also contain suspended or settling faecal or waste matter, which may interfere with the sensitive and fragile sensors required for EC measurements.

In spite of these issues, the EC method has the potential to provide true in situ measurements of benthic oxygen fluxes. The goal of this study was to compare benthic oxygen flux measurements and chemical indicators of sediment enrichment in order to investigate if the EC method is a useful and practical tool for evaluating benthic impacts from salmon farms. Oxygen fluxes are compared with sediment $C$, $\mathrm{N}, \mathrm{P}$ and free sulphide concentrations across an enrichment gradient at a salmon farm in a high-flow location. Comparison was also made between a highflow and low-flow location where low near-bed turbulence may increase the diffusive boundary layer thickness and inhibit oxygen flux to the sediments. In addition, recommendations are made for applying the EC method in future aquaculture studies.

\section{MATERIALS AND METHODS}

\subsection{Study sites}

Measurements were made near 2 salmon farms located in the Queen Charlotte Sound, New Zealand. The high-flow farm is located on the southern side of 


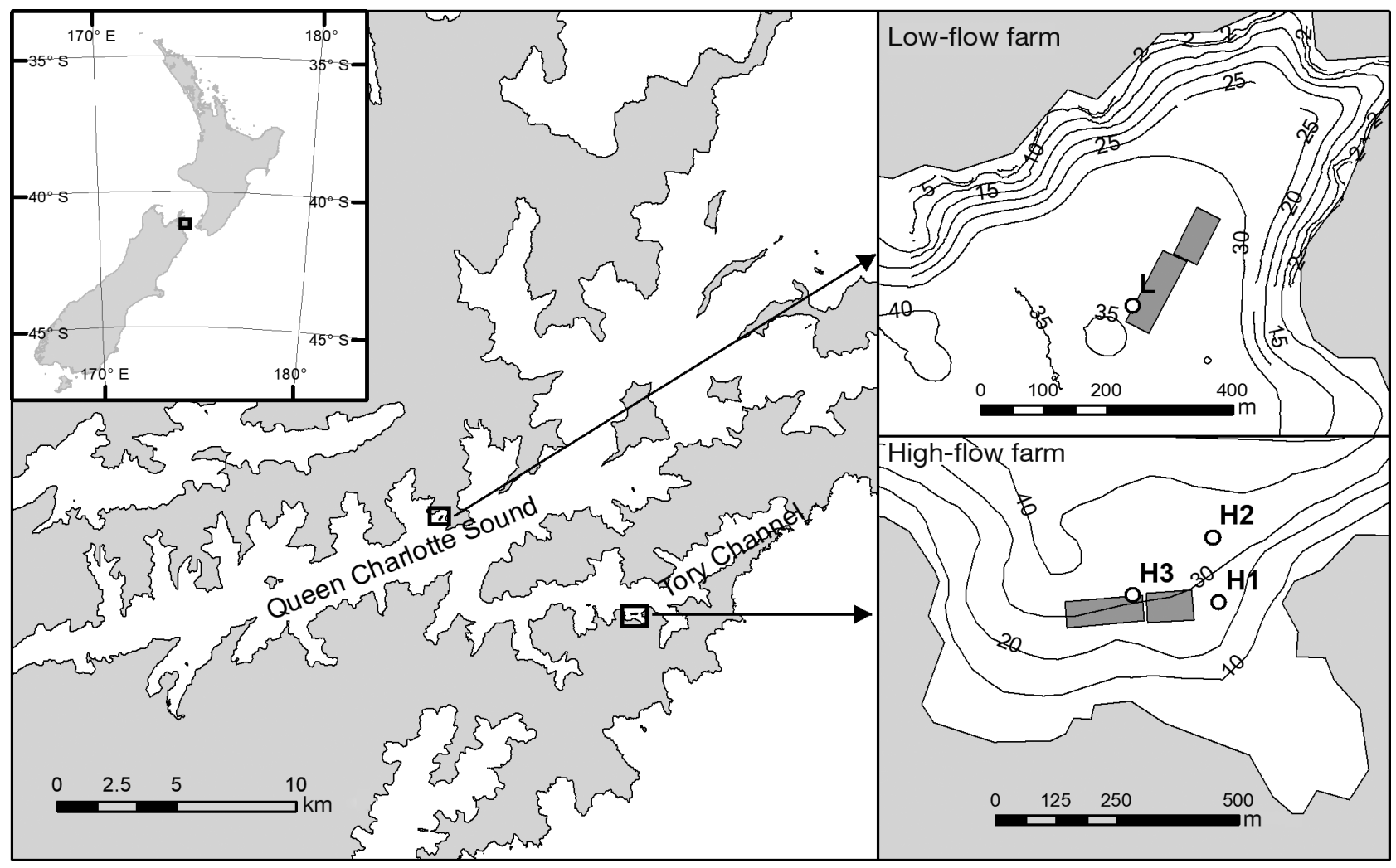

Fig. 1. Location of the 2 study sites and the EC systems in the Marlborough Sounds in New Zealand. The high-flow site is in the strongly tidal Tory Channel, while the low-flow site is in an embayment in Queen Charlotte Sound. Grey boxes are the fish farms

the Tory Channel, which is the southern entrance to the Queen Charlotte Sound (Fig. 1). Due to a phase difference of $\sim 50^{\circ}$ between the seaward ends of the Queen Charlotte Sound and the Tory Channel (Plew \& Stevens 2013), the Tory Channel experiences strong peak tidal flows of $20000 \mathrm{~m}^{3} \mathrm{~s}^{-1}$ (neap) to $30000 \mathrm{~m}^{3} \mathrm{~s}^{-1}$ (spring) (Hadfield et al. 2014) through a channel of $\sim 1 \mathrm{~km}$ width and $40 \mathrm{~m}$ average depth. The channel is vertically well mixed, with wind driving sub-tidal flows that are small compared to the tidal flows (mean: $660 \mathrm{~m}^{3} \mathrm{~s}^{-1}$, peaks of $\sim 2000 \mathrm{~m}^{3} \mathrm{~s}^{-1}$ ). Near the farm, mid-depth mean water speeds of $15 \mathrm{~cm} \mathrm{~s}^{-1}$ and maximum $55.9 \mathrm{~cm} \mathrm{~s}^{-1}$ are reported by Keeley et al. (2012a). This 1.5 ha farm consists of 2 connected rigid steel superstructures supporting twelve $15 \times$ $15 \mathrm{~m}$ flexible net cages and a further six $20 \times 20 \mathrm{~m}$ cages. The farm has been operating since 1992, expanded in 2009, and currently produces around $2000 \mathrm{t} \mathrm{yr}^{-1}$ of Chinook salmon Oncorhynchus tshawytscha. Feed levels vary between 2300 and $4700 \mathrm{t}$ $\mathrm{yr}^{-1}$ depending on stocking rates (Keeley et al. 2013), with a permitted maximum amount of $6000 \mathrm{t} \mathrm{yr}^{-1}$. Water depths vary from 27 to $31 \mathrm{~m}$ across the site.

Measurements were also taken at a low-flow farm located in an embayment on the main arm of the
Queen Charlotte Sound (Fig. 1). This farm has been operating since $\sim 1985$ and currently covers an area of 2.0 ha with twenty $20 \times 20 \mathrm{~m}$ steel net pens. Feed levels range between 1900 and $3300 \mathrm{t} \mathrm{yr}^{-1}$ (Keeley et al. 2013), with a permitted maximum amount of $4000 \mathrm{t}$ $\mathrm{yr}^{-1}$. It currently produces $1000 \mathrm{t} \mathrm{yr}^{-1}$. Water depth is $\sim 35 \mathrm{~m}$, and mid-depth mean current water speeds are $3.7 \mathrm{~cm} \mathrm{~s}^{-1}$, maximum $17.5 \mathrm{~cm} \mathrm{~s}^{-1}$ (Keeley et al. 2012a).

Four deployments of the EC system were made at the high-flow farm. Two of these were taken at nearly the same location (H1), but challenges in deploying instrumentation at $\sim 30 \mathrm{~m}$ depth from a small boat in strong tidal currents meant there was up to $10 \mathrm{~m}$ distance between them. These deployments are reported here as H1a and H1b. This site was $50 \mathrm{~m}$ east of the farm perimeter. Site H2 was 120 m northeast of the farm, while H3 was immediately adjacent the farm. These sites were selected to cover an expected gradient of benthic enrichment within the farm footprint, as reported by Keeley et al. (2013), and to avoid the risk of tangling with mooring lines holding the structures in place. One deployment was made at the low-flow farm. This site (L) was also immediately adjacent the farm where the highest benthic enrichment was expected. The shortest deployment (H1b) was 
$18.5 \mathrm{~h}$, although 2 deployments at this location mean that $42.5 \mathrm{~h}$ of data were obtained here. The longest deployment was for $92.25 \mathrm{~h}$ at Site H2. For further details of the deployments, see Table 1, and for the locations relative to the farms, see Fig. 1.

\subsection{Instrumentation}

The principle behind the $\mathrm{EC}$ technique is that a vertical flux can be determined by time-averaging the products of the fluctuations in vertical velocity and a scalar from their respective means (Berg et al. 2003, Kuwae et al. 2006). The velocity and the scalar (in this case, oxygen concentration) are measured simultaneously at as close to the same location as practical and at sufficiently high frequency to resolve the turbulent fluctuations. Velocity was measured using a Nortek Vector acoustic Doppler velocimeter (ADV) with a cylindrical sample volume $\sim 15 \mathrm{~mm}$ in height and diameter, located $150 \mathrm{~mm}$ below the instrument head. Oxygen concentrations (and water temperature) were recorded using a fast-response optode with a reported $90 \%$ response time of $0.51 \mathrm{~s}$ (RINKO-EC, JFE Advantech) located $15 \mathrm{~mm}$ from the edge of the ADV sample volume (Berg et al. 2016). Simultaneous oxygen measurements were made with a galvanic oxygen probe (AMT Analysenmesstechnik) for one deployment. The ADV and fast-response oxygen sensor were mounted to a tripod with the sample volume of the ADV 150 mm above the seafloor. Additional instruments were fitted to one of the legs of the tripod to measure $\mathrm{pH}$ (AMT Analysenmesstechnik), reference temperature and DO using a slower-responding but more stable optode (RINKO ARO-III, JFE Advantech). All the above sensors were connected to a logger (Rockland Scientific) which recorded all outputs continuously at $64 \mathrm{~Hz}$. The ADV was set to burst mode, recording 27280 samples at $64 \mathrm{~Hz}$ (burst duration of $895 \mathrm{~s})$ with a $5 \mathrm{~s}$ interval between bursts so that the range to the bed could be measured. A separate selflogging instrument mounted on the tripod $\sim 1 \mathrm{~m}$ above the seabed measured conductivity, temperature and depth (RBR concerto logger, 30 s intervals) and 2 sensors mounted on the top of the frame measured photosynthetically active radiation (PAR) (DEFI PAR, JFE Advantech, logging at $30 \mathrm{~s}$ intervals, and ECO-PAR at 10 min intervals). A second DEFI PAR sensor was installed on a wharf near the high-flow farm, $\sim 3 \mathrm{~m}$ above water level, to record ambient light.

The tripod was lowered to the seafloor from a small $(7.1 \mathrm{~m})$ boat and retrieved using a rope either tied to the farm structure or brought to the surface by acoustic release (LRT, Sonardyne). Attempts were made to orient the instrument array using a large fin mounted to the tripod. The intention was that currents acting on this fin while lowering the array to the seabed would orient the array with the oxygen sensor downstream of the ADV sample volume, at least for part of the tide.

\subsection{Flux calculations}

Data were first split into 15 min bursts. Output from the fast-response oxygen sensor was converted to concentration in $\mu \mathrm{M}$ using the method desc ribed in the manufacturer's manual (JFE Advantech 2017). While this sensor was calibrated prior to deployment, there was a slow drift in calibration (reaching $8 \%$ by the end of the final deployment). This calibration drift was corrected by scaling oxygen concentrations for each burst to match the measurements from the reference oxygen sensor (RINKO ARO-III), which retained its calibration over the deployments.

The velocity data were despiked using a phasespace filter (Goring \& Nikora 2002). Spikes were replaced by linear interpolation. No despiking was required for the oxygen data.

The $64 \mathrm{~Hz}$ data were averaged to $8 \mathrm{~Hz}$ to reduce the signal-to-noise ratio and reduce computation effort in subsequent processing steps (Berg et al. 2009).

The velocity data were rotated to obtain the velocity component normal to the local streamline, which is assumed to be parallel to the bed. This prevents strong horizontal flux components being projected into the vertical direction. In order to do this, burst means for each velocity component were calculated, then a planar-fit transformation (Wilczak et al. 2001, Lorke et al. 2013) was applied to determine the tilt and pitch rotation required to orient the velocity data such that vertical velocities were normal to the bed. The rotations were calculated for each deployment and applied to all bursts.

In steady, uniform conditions with a well-developed boundary layer, the transport equation for oxygen reduces to

$$
J_{\text {ec }}=\overline{W^{\prime} C^{\prime}}
$$

where $w^{\prime}$ and $C^{\prime}$ are the instantaneous fluctuations of the vertical velocity $w(t)$ and oxygen concentration $C(t)$ (where $t$ denotes time) from their respective mean values, $W$ and $C$ (i.e. $W^{\prime}=w(t)-W, C^{\prime}=C(t)-$ $C$ ), and $J_{\text {ec }}$ is the turbulent flux (Berg et al. 2003). The overbar in Eq. (1) indicates time-averaging. Mean removal requires first calculating an appropriate 
timescale that separates the higher-frequency fluxtransporting turbulent eddies from larger-scale advective motions (McGinnis et al. 2008, Lorrai et al. 2010). Common approaches include progressively increasing the averaging window size until the covariance of $w^{\prime}$ and $C^{\prime}$ (i.e. the turbulent flux) and/ or shear velocity converges (Attard et al. 2014, Rovelli et al. 2017), or selecting a timescale from inspection of the power spectra of vertical velocity fluctuations or co-spectra of $w^{\prime}$ and $C^{\prime}$ (Lorke et al. 2013). The fluctuations $W^{\prime}$ and $C^{\prime}$ are then calculated using either simple (block) averaging or linear detrending to remove means within each window, or by subtracting a running average (Holtappels et al. 2013, McGinnis et al. 2014).

The data here were collected from a strongly tidal environment, with currents at the study sites influenced by large-scale velocity fluctuations resulting from eddy shedding from headlands and possibly by the farm structure. Similar low-frequency fluctuations also occur in the oxygen data (see Section 3.1). The spectral band of the eddy range is velocitydependent (narrower at higher velocities) (Lorrai et al. 2010). Therefore, instead of applying a constant averaging window across the entire dataset, a similar approach to McGinnis et al. (2014) was adopted and the frequency range of the flux-containing eddies was calculated for each 15 min burst. Then a running mean with a window length equal to twice the period of the largest eddies was subtracted. Following Lorrai et al. (2010), the period of the largest eddies $\left(\tau_{\mathrm{L}}\right)$ was calculated as

$$
\tau_{\mathrm{L}}=z / u_{*}
$$

and the shear velocity $u_{*}$ was calculated from the turbulent kinetic energy dissipation rate $\varepsilon$, height above the bed $z$, and the von Karman constant $(\kappa=0.4)$,

$$
u_{*}=(\varepsilon \kappa z)^{1 / 3}
$$

The dissipation rate was calculated for each burst using the inertial dissipation method (Bluteau et al. 2011). The length of this window averaged $\sim 60 \mathrm{~s}$ at the high-flow sites $(\mathrm{H} 1-\mathrm{H} 3)$ and $140 \mathrm{~s}$ at Site L. After subtracting the running mean from the velocity and oxygen data, the flux was calculated from the covariance of $W^{\prime}$ and $C^{\prime}$ for each $15 \mathrm{~min}$ burst. Increasing the window length beyond $2 \tau_{\mathrm{L}}$ induced only minor change to fluxes averaged over each deployment but increased the variability between bursts (increasing the window 3 -fold causes a $10 \%$ change in mean fluxes at Site L but increased SE by $50 \%$ ).

To account for the time lag caused by the physical separation between the ADV sampling volume and the oxygen sensor, and the response time of the oxygen sensor, the oxygen data were shifted in time relative to the velocity data to achieve the maximum correlation between the time series (McGinnis et al. 2008). The shift was limited to a maximum of $4 \mathrm{~s}$.

Advection of water masses with different oxygen concentrations past the sensor can create a vertical flux term that is included in the measured flux in addition to the benthic flux (Holtappels et al. 2013). In a boundary layer flow, a horizontal gradient in oxygen also develops a vertical gradient because water moves faster with increasing distance from the bed. This vertical gradient would then result in a turbulent vertical flux. In a steady flow, the size of this transient flux term $\left(J_{t}\right)$ can be estimated from

$$
J_{t}=\frac{\partial C}{\partial t} z \frac{\ln \left(z / z_{\mathrm{up}}\right)}{\ln \left(z_{\mathrm{up}} / z_{0}\right)-1}
$$

where $z_{\mathrm{up}}$ is the upper limit of the benthic boundary layer, and $z_{0}$ is the hydraulic roughness (Holtappels et al. 2013). Increasing concentrations result in a downward (negative) flux. $z_{\mathrm{o}}$ was calculated from the shear velocity (calculated from the dissipation rate as described in Eq. 3) and streamwise velocity $(U)$ for each burst, assuming a logarithmic boundary layer velocity profile:

$$
U(z)=\frac{u_{*}}{\kappa} \ln \left(\frac{z}{z_{0}}\right)
$$

There was considerable variability in $z_{0}$ between bursts, so for each site, a regression was fit between streamwise velocity and $z_{0}$. An example of this is shown for Site H2 in Fig. 2. These regressions were then used to calculate a value of $z_{\mathrm{o}}$ for each burst that is applied to calculate the transient flux correction term from Eq. (4). An upper bound of $z_{0}<0.001 \mathrm{~m}$ was applied, which typically corresponded to a streamwise velocity of $0.05 \mathrm{~m} \mathrm{~s}^{-1}$, as the high $z_{0}$ values at low speeds may indicate situations where turbulence was not well developed. The transient flux correction term is weakly influenced by the boundary layer height $z_{\mathrm{up}}$. A value of $5 \mathrm{~m}$ was used here. The transient flux term is calculated for each burst. The corrected flux is (Holtappels et al. 2013):

$$
J=J_{\text {ec }}-J_{t}
$$

\subsection{Sediment properties}

Sediment cores were obtained from each site using a small NIOZ mono corer (Royal Netherlands Institute for Sea Research). The upper $3 \mathrm{~cm}$ from 3 cores at each site were combined, and analysed in the lab- 


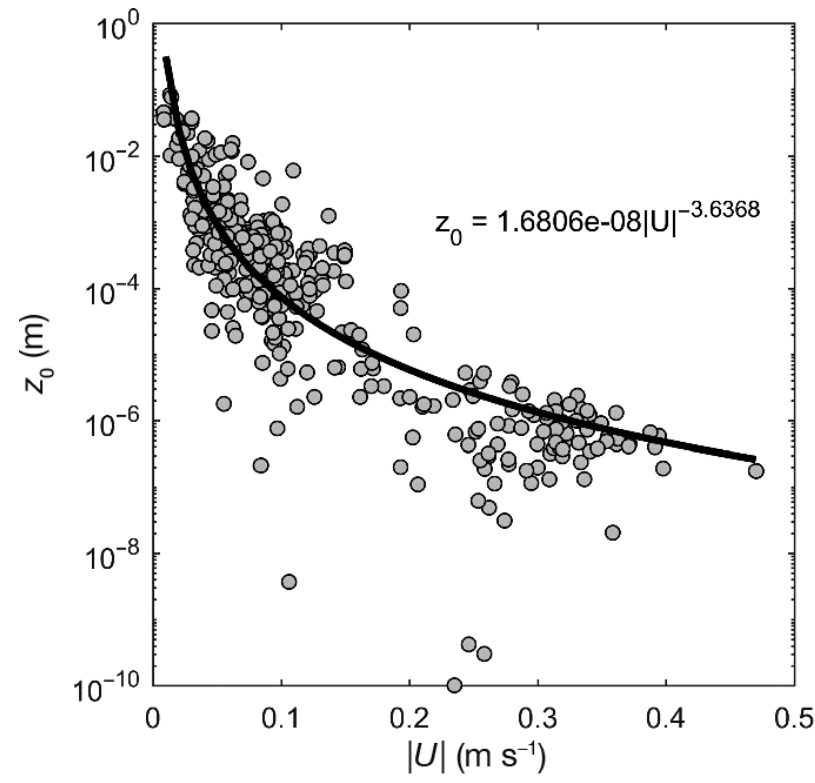

Fig. 2. Roughness height $\left(z_{0}\right)$ plotted against current speed $(U)$ at site H2. Roughness height is calculated from shear velocity. The solid line and equation show a least-squares regression fit to the data

oratory for particulate $\mathrm{N}(\mathrm{PN})$, particulate $\mathrm{C}(\mathrm{PC})$, and total recoverable $\mathrm{P}$ (TRP). A further 3 samples from each site were analysed for sulphide concentrations (TS). The average TS concentrations are reported here. PN and PC were processed in an Elementar $\mathrm{C} / \mathrm{N}$ analyser following procedure MAM, 01-1090. TRP was measured in an inductively coupled plasma mass spectrometer following US EPA Method 200.2. Samples analysed for sulphide were prepared by solubilising in a high-pH solution containing a chelating agent and an anti-oxidant, and sulphides measured using a calibrated electrode. Loss on ignition was also measured by drying samples to constant weight at $104^{\circ} \mathrm{C}$, then heating to $400^{\circ} \mathrm{C}$ for $6 \mathrm{~h}$.

Sedimentation rates were also measured at locations near the EC deployments at the high-flow farm. PVC tubes (65 $\mathrm{mm}$ diameter, $650 \mathrm{~mm}$ length) were suspended vertically in pairs $1 \mathrm{~m}$ above the sediment surface. These were deployed for $12 \mathrm{~d}$. Sediment was collected in jars attached to the bottom of each tube. The jars were filled with $10 \%$ formalin solution to preserve material that was collected. Samples were dried and weighed, then analysed for PN, PC and TRP using the methods described for the sediment cores.

\subsection{Benthic enrichment scale}

Keeley et al. (2012b) developed an enrichment scale (ES) for benthic impacts under New Zealand salmon farms. This scale ranges from ES1: natural pristine conditions, to ES7: severe enrichment (azoic/ abiotic; sediments no longer capable of supporting macrofauna). Maximum biodiversity occurs at low (1-3) ES scores, and abundance peaks around ES5. Above ES6, species richness and diversity are very low, and total macrofauna abundance decreases from peak values. The ES score is determined from several variables, many of which are biological indicators, but is strongly correlated to sulphide concentrations (Keeley et al. 2012a). In the present study, the ES score is estimated from sulphide concentrations according to the following equation from Keeley et al. (2012a):

$$
\mathrm{ES}=(\ln (S)-a) / b
$$

$S$ is the free sulphide concentration in the sediments $\left(\mathrm{S}^{2-}, \mu \mathrm{M}\right)$ and $a$ and $b$ are coefficients. Keeley et al. (2012a) give different coefficients for high- and low-flow sites. Low-flow sites had mean velocities $<0.09 \mathrm{~m} \mathrm{~s}^{-1}$ and high-flow sites had mean velocities $>0.15 \mathrm{~m} \mathrm{~s}^{-1}$ measured at $20 \mathrm{~m}$ water depth. The highand low-flow sites in the present study were included and similarly defined in the study by Keeley et al. (2012a). The coefficients for high-flow sites are $a=$ $2.354, b=1.072$, and for the low-flow sites: $a=3.977$, $b=0.689$.

\section{RESULTS}

\subsection{Hydrodynamic conditions}

Burst-averaged values of water depth, velocity components, temperature, salinity, DO and $\mathrm{pH}$ are shown in Fig. 3, and deployment averaged values are reported in Table 1. Sites H1 (a and b) and H2 had similar mean current speeds, although higher peak velocities were recorded at $\mathrm{H} 2$. Velocities at H3 (next to the farm) were $~ 30 \%$ lower than $\mathrm{H} 1$ and $\mathrm{H} 2$, but considerably higher than at the low-flow site (L). Current speeds at all high-flow sites were typically strongest on the rising tide. At $\mathrm{H} 1$, the fastest current speeds were observed mid-rising tide. At $\mathrm{H} 2$, there was a distinctive double peak in current speed on the rising tide, indicative of a large-scale eddy consistently passing the site at the same phase of the tide. Closest to the farm (H3), the fastest currents occurred 1-2 $\mathrm{h}$ before high tide. Velocities at Site L appear to be less correlated with tides (although the time series is too short for a tidal decomposition).

Common characteristics at all sites were tidal variations in temperature, salinity, $\mathrm{DO}$ and $\mathrm{pH}$. At the 


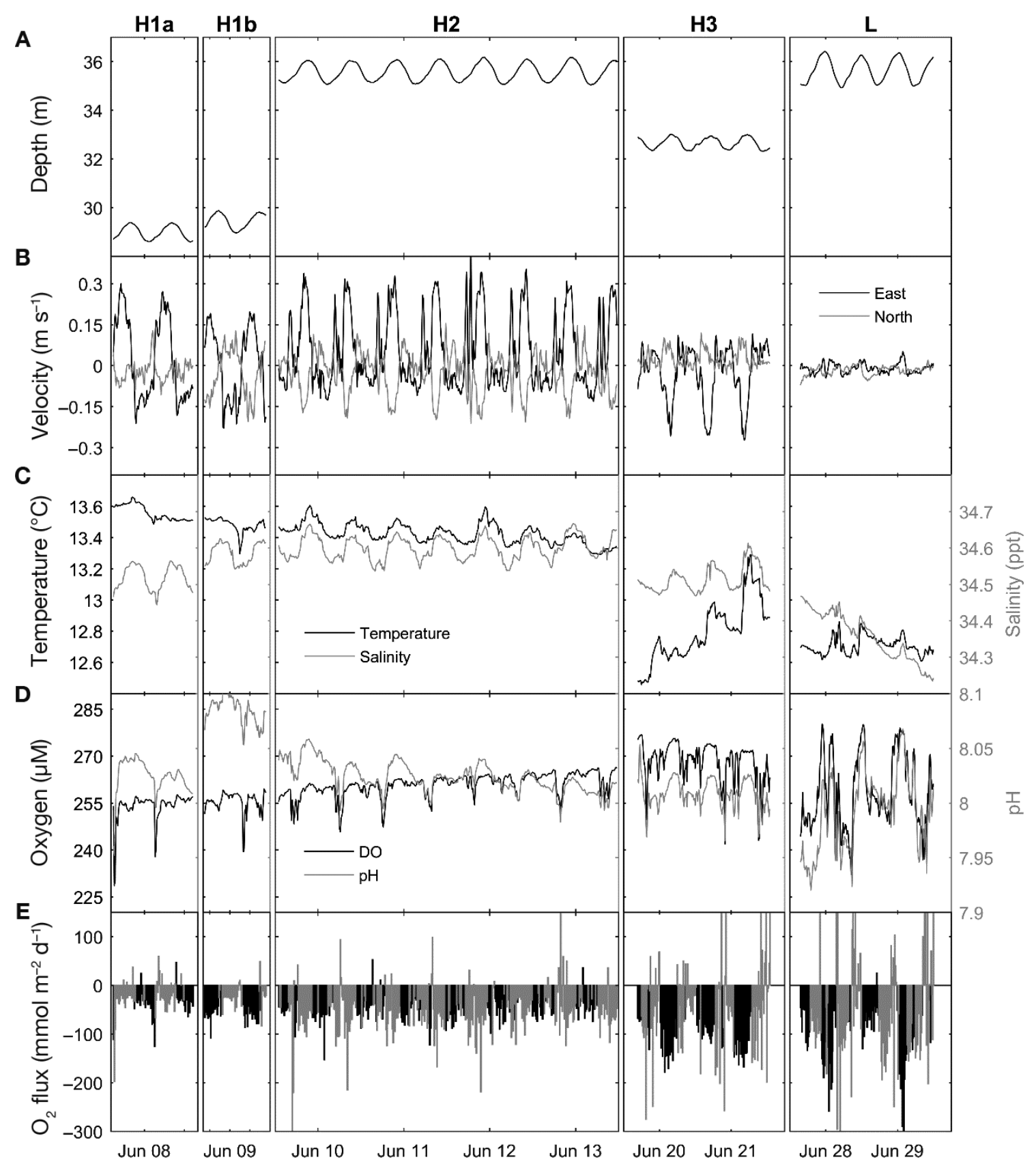

Fig. 3. Burst-averaged values of (A) water depth, (B) east and north water velocity, (C) water temperature and salinity, (D) dissolved oxygen and $\mathrm{pH}$ and (E) oxygen flux (negative values indicating a downward flux and unreliable fluxes shown in grey)

high-flow sites (H1-H3), temperature and salinity variations were in phase with the tide, with lowest temperatures and salinities observed at low tide. This was likely related to the strong tidal flow through the adjacent Tory Channel. During the falling tide, cooler fresher water from the inner sound flows seaward. As the tide rises, the flood tide brings warmer, saline ocean water into the channel. Longitudinal gradients in temperature and salinity due to mixing in the channel result in the smoothed fluctuations observed here. DO and $\mathrm{pH}$ show a distinct dip that occurs on the rising tide at Sites $\mathrm{H} 1$ and $\mathrm{H} 2$, and at or slightly before low tide at H3. The magnitude of this dip in $\mathrm{DO}$ and $\mathrm{pH}$ decreases with increasing distance from the farm $(\mathrm{H} 3<\mathrm{H} 1<\mathrm{H} 2)$. It is likely that the lower oxygen concentrations were caused by the arrival of deoxygenated water from the farm (due to a combination of benthic metabolism and respiration 


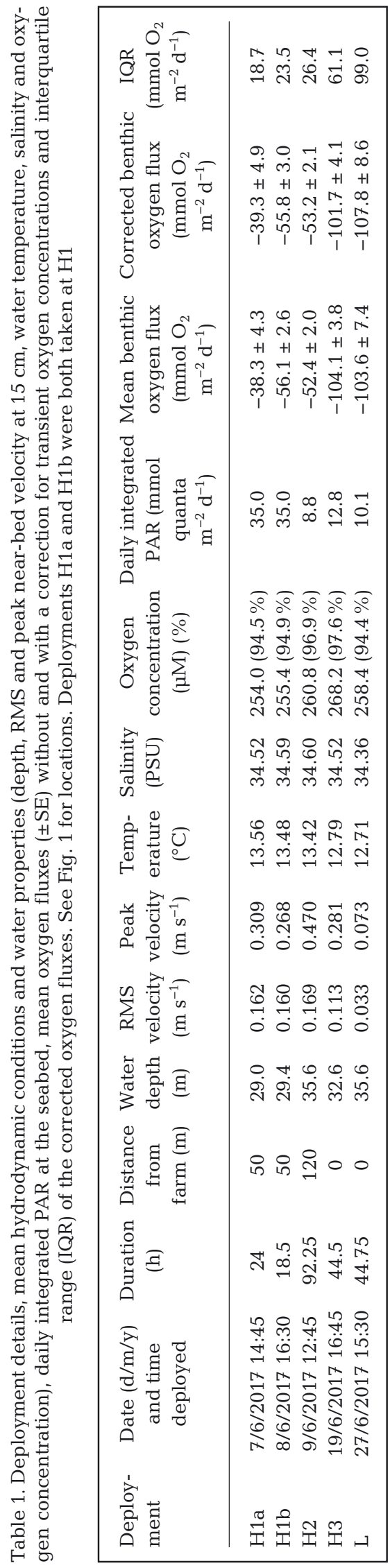

of the fish in the farm cages). On the flood tide when current speeds increased, this low-oxygenated water was detected at Site $\mathrm{H} 1 \sim 2 \mathrm{~h}$ after low tide, and at $\mathrm{H} 2$ $\sim 3.5 \mathrm{~h}$ after low tide.

The gradual increase in oxygen concentrations during the deployments at $\mathrm{H} 1$ and $\mathrm{H} 2$ (Fig. 3D) corresponds to slowly decreasing water temperature (Fig. 3C). The opposite trend was seen a week later at $\mathrm{H} 3$ when temperatures warmed. Oxygen saturation (concentration as \% of saturation concentration) did not show these trends, confirming that the gradual changes in oxygen concentrations were caused by temperature.

Over the $2 \mathrm{~d}$ deployment at Site L, salinity decreased but there was no obvious trend in temperature. Small peaks in temperature and salinity coincided with high tide. Oxygen concentrations and $\mathrm{pH}$ aligned, with both showing peaks at high tide, and minimums at or shortly after low tide. Fluctuations in burst-averaged oxygen and $\mathrm{pH}$ were larger than at the high-flow sites.

Dissolved oxygen and $\mathrm{pH}$ were strongly correlated, particularly at the farm sites H3 and L (Fig. 4). This association could be driven by either carbonate chemistry, with higher $\mathrm{CO}_{2}$ concentrations likely in the lower $\mathrm{O}_{2}$ waters resulting from a combination of benthic and pelagic (i.e. fish stock) respiration, or release of $\mathrm{H}_{2} \mathrm{~S}$ from sediments under anoxic conditions, which at high $\mathrm{pH}$ would rapidly dissociate into $\mathrm{H}^{+}$ and $\mathrm{HS}^{-}$. While it is not possible to determine which mechanism dominates from our data, it is more likely that the low $\mathrm{pH}$ originates from respiration, i.e. $\mathrm{CO}_{2}$, particularly considering the high biomass of fish farmed near the measurement locations.

\subsection{Light}

The data presented here were collected in the southern hemisphere winter when incoming PAR was near its annual minimum. Daily maximum incoming PAR (above the water) varied between 200 and $1400 \mu \mathrm{mol} \mathrm{m}^{-2} \mathrm{~s}^{-1}$ and typically reached a daily peak of $800 \mu \mathrm{mol} \mathrm{m}^{-2} \mathrm{~s}^{-1}$. Daily integrated surface radiation varied between 3200 and $16800 \mathrm{mmol} \mathrm{m}^{2} \mathrm{~d}^{-1}$.

The 2 sensors deployed on the mooring gave similar peak and average PAR during daylight hours. The ECOPAR had greater resolution and a lower detection limit $\left(0.04 \mu \mathrm{mol} \mathrm{m}{ }^{-2} \mathrm{~s}^{-1}\right)$ than the DEFI $(0.3 \mu \mathrm{mol}$ $\mathrm{m}^{-2} \mathrm{~s}^{-1}$ ), and consequently, only the values from the ECOPAR are reported in Table 1. Daily integrated PAR values have been calculated using data recorded when surface PAR $>1 \mu \mathrm{mol} \mathrm{m}^{-2} \mathrm{~s}^{-1}$ to reduce 


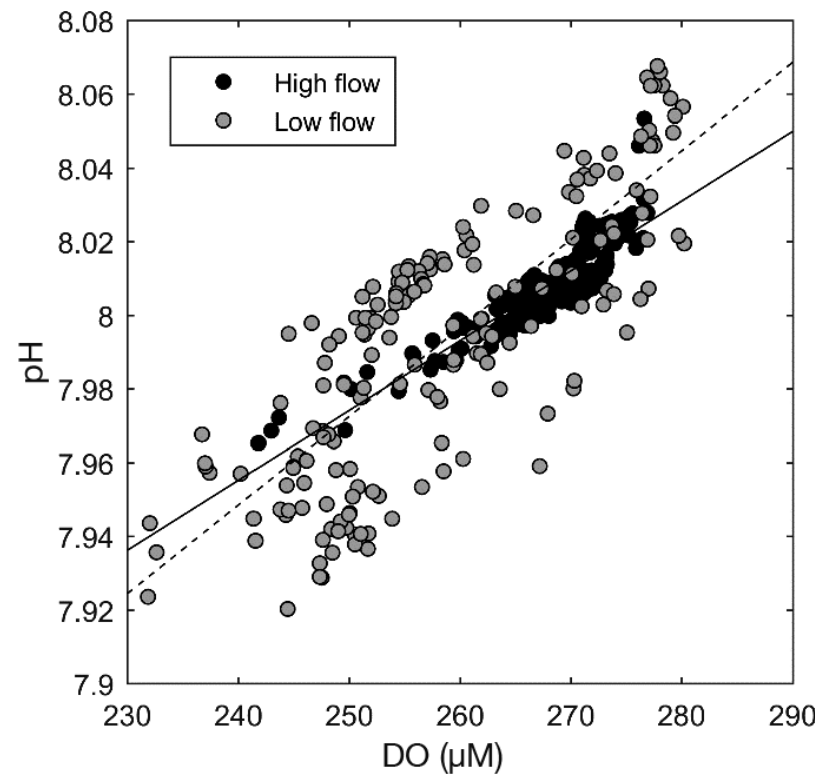

Fig. 4. Example of correlation between $\mathrm{pH}$ and oxygen concentrations. Burst-averaged $\mathrm{pH}$ and dissolved oxygen (DO) concentration adjacent to the farms at the high-flow site H3 and low-flow site L. Solid line: best-fit regression for the high-flow site $\left(\mathrm{R}^{2}=0.816\right.$, RMSE $\left.=0.0058\right)$; dashed line: best fit for the low-flow site $\left(\mathrm{R}^{2}=0.634, \mathrm{RMSE}=0.0217\right)$

bias from noise. These values are calculated over either a single $24 \mathrm{~h}$ period or averaged over multiple $24 \mathrm{~h}$ periods for the longer deployment at Site H2. Daily integrated PAR at the seabed were low, ranging between $35 \mathrm{mmol}$ quanta $\mathrm{m}^{-2} \mathrm{~d}^{-1}$ at $\mathrm{H} 1$ and 8.8 mmol quanta $\mathrm{m}^{-2} \mathrm{~d}^{-1}$ at H2. Peak PAR at the seabed reached $2.0 \mu \mathrm{mol}$ quanta $\mathrm{m}^{-2} \mathrm{~s}^{-1}$ at $\mathrm{H} 1$, and $<1 \mu \mathrm{mol}$ quanta $\mathrm{m}^{-2} \mathrm{~s}^{-1}$ at H2, H3 and L.

Based on peak and daily integrated values, only $0.1-0.2 \%$ of incoming PAR reached the seafloor.

\subsection{Oxygen fluxes}

Fluxes calculated from each burst are shown in Fig. 3E. The fluxes were highly variable, with many values indicating positive fluxes. It is unlikely that there was sufficient light reaching the seabed to stimulate primary production, and the positive fluxes occur during day and night, so were more likely an artefact of the measurements. Berg et al. (2016) caution that due to the large size of the RINKO-EC oxygen sensor, it should not be positioned directly upstream of the ADV's sampling volume as it may affect the velocity measurements. They also noted that flux reductions sometimes, but not always, arose when the sensor was pointed downstream. In the present study, nearly all the positive (upwards) fluxes, and greater variability in fluxes, were observed when the sensor was upstream of the ADV sample volume. An effective filter that separated upstream and downstream oriented flows was to accept fluxes when the velocity component in the direction of the oxygen sensor $\left(U_{\mathrm{x}}\right)$ was $U_{\mathrm{x}}>0.01 \mathrm{~m} \mathrm{~s}^{-1}$ (Fig. 5). Setting this threshold $\left(0.01 \mathrm{~m} \mathrm{~s}^{-1}\right)$ greater than zero also removed unreliable fluxes at low velocities. This threshold worked similarly well at both high-flow and low-flow sites (Fig. 5).

A large proportion (57\%) of the flux measurements were rejected using this threshold (Fig. 3E). While many of the rejected flux measurements (shown as grey in Fig. 3E) are of similar magnitude to those retained, the average of the rejected fluxes were smaller (by between 30 and $60 \%$ ) than the retained values across all sites, apart from at $\mathrm{H} 2$, where they were of the same magnitude but more variable (standard errors were 4.6 and $10.3 \mathrm{mmol} \mathrm{m}^{-2} \mathrm{~d}^{-1}$ for the accepted and rejected fluxes, respectively).

Because many of the flux estimates were rejected due to unfavourable current direction, there remained only limited periods of continuous flux measurements where interactions between velocity or ambient oxygen concentrations and fluxes could be investigated. Linear regression was used to look for relationships between flow speed, ambient oxygen concentrations as independent variables, and oxygen fluxes as the response. The only site with a statistically significant $(p<0.0001)$ relationship between flux and velocity was site H3, with negative fluxes increasing with velocity (Fig. 6A). Site L did not show a statistically significant relationship between flux and velocity, but did show fluxes increasing in magnitude with increasing burst-averaged oxygen concentration (Fig. 6B). Consistent with the low seabed PAR values (Table 1), no difference in benthic oxygen flux was detected between day and night, and thus primary production is assumed to be negligible at these sites.

The galvanic oxygen sensor deployed alongside the optode during deployment H1a showed good agreement for the first $2 \mathrm{~h}$, with accumulated fluxes within $3 \%$. Beyond this time, no fluxes could be extracted from the galvanic sensor. Inspection of the sensor after deployment showed that some substance had coated the sensor, impacting its ability to respond to oxygen fluctuations. I have observed this same coating forming on this type of sensor at other deployments around salmon farms. The coating has not yet been identified but could be from faecal matter or oils and fats originating from the salmon farm. This coating on galvanic sensors prompted me to try optode systems in this environment. 

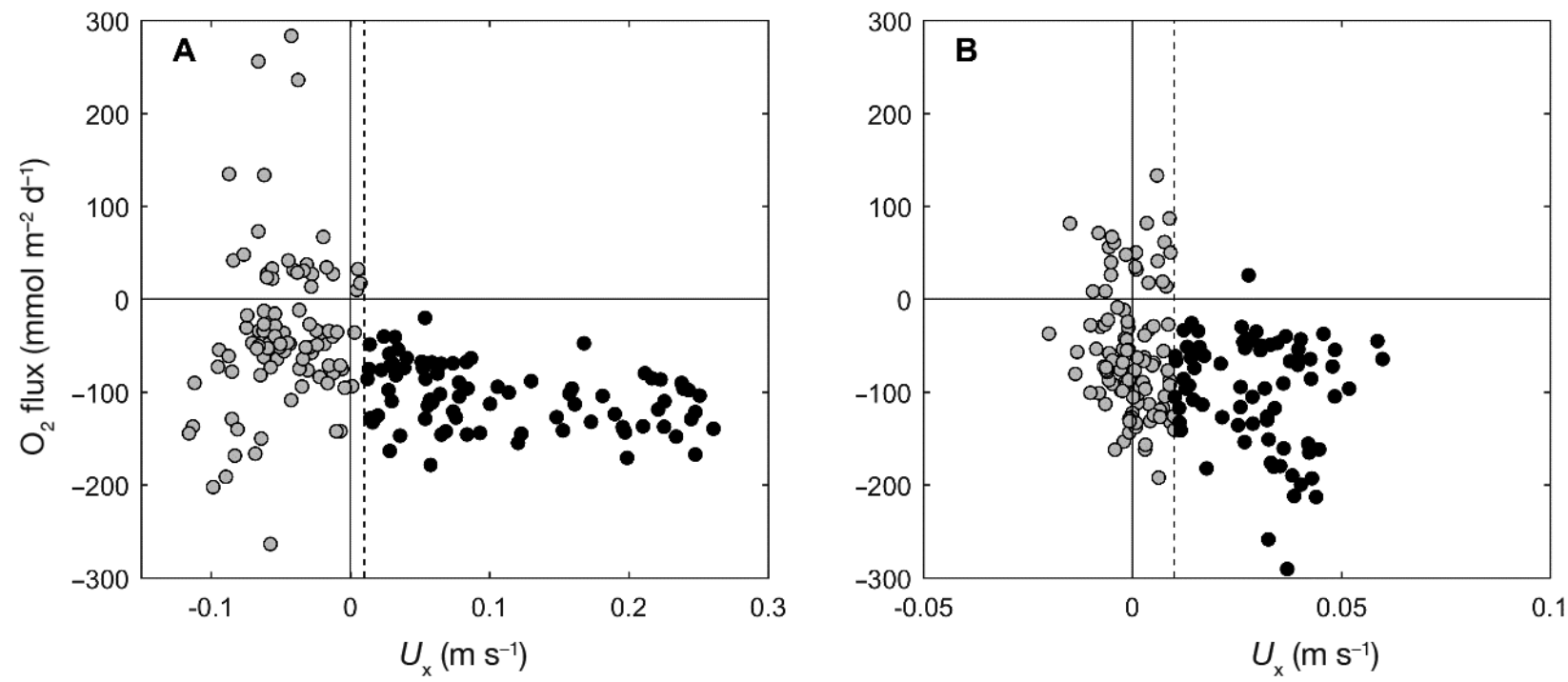

Fig. 5. Fluxes plotted against the velocity component aligned along the axis $\left(U_{\mathrm{x}}\right)$ of the fast-response oxygen sensor at (A) site $\mathrm{H} 3$ and (B) site L. Fluxes shown as solid black circles are when the on-axis velocity $>0.01 \mathrm{~m} \mathrm{~s}^{-1}$ (vertical dashed line)
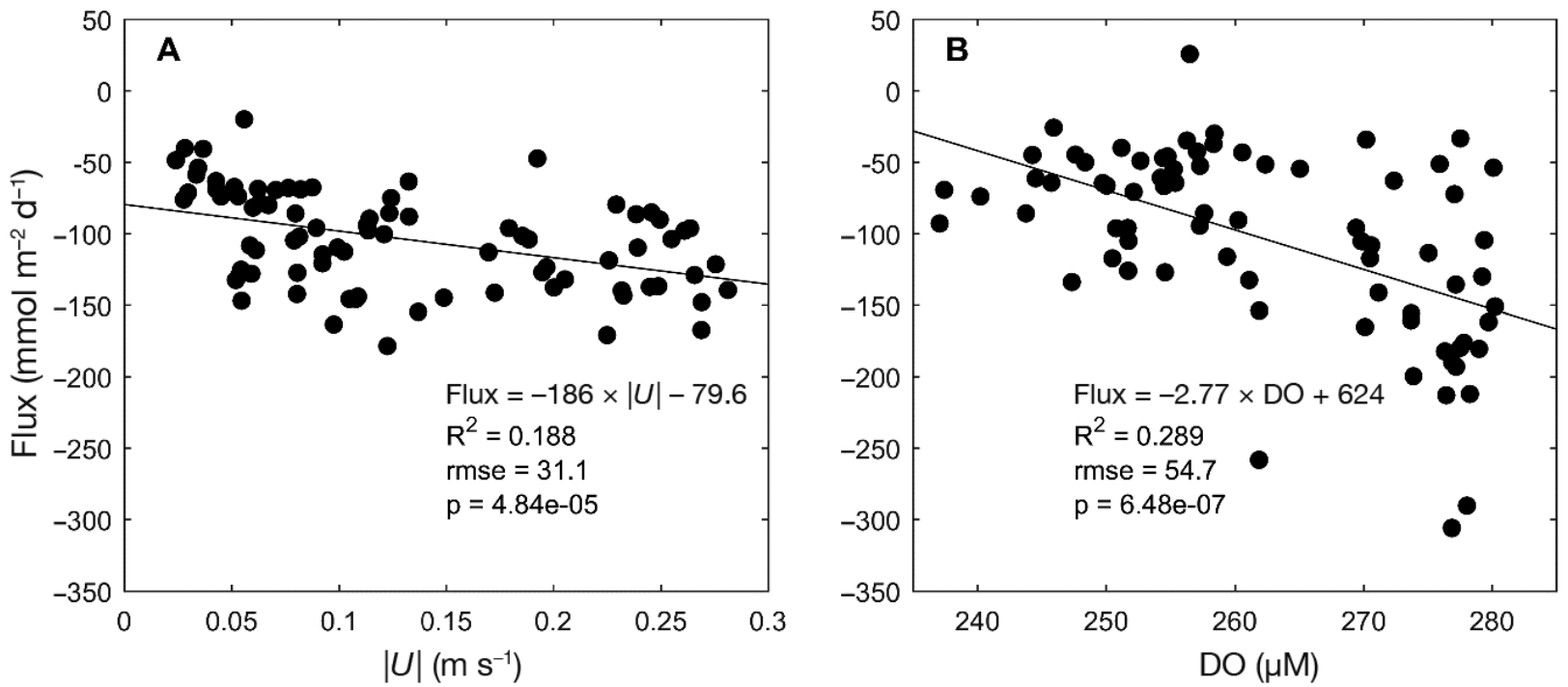

Fig. 6. Flux versus (A) current speed $(U)$ at site H3 and (B) dissolved oxygen (DO) concentration at Site L. The solid lines show best fit linear regressions

Oxygen fluxes averaged over each deployment are reported in Table 1. Mean fluxes at H1a and H1b differed by $30 \%$. At the high-flow sites, fluxes were lowest at site H1, and highest at H3. Fluxes at the low-flow site (L) were equivalent to those at H3. Table 1 also gives mean fluxes with and without the correction for transient oxygen concentrations, which demonstrates this term has little influence on mean fluxes. The interquartile range is provided as an indicator of the variability of fluxes (Table 1). At the highflow sites, this variability generally increased both in magnitude and as a ratio of the mean flux as mean flux increased. Highest variability occurred at L.

\subsection{Sedimentation rates}

Sedimentation rates of $\mathrm{C}, \mathrm{N}$ and $\mathrm{P}$ at the high-flow sites were lowest at $\mathrm{H} 1$ and highest at H3 (Table 2). $\mathrm{H} 1$ had lower settlement than H2, despite being located closer to the farm. This appears consistent with maps of observed or modelled deposition from previous studies (Keeley et al. 2013, Hadfield et al. 2014), indicating currents carry waste north-eastward from the farm rather than eastward.

As sedimentation rates increased, $\mathrm{C}, \mathrm{N}$ and $\mathrm{P}$ content also increased. Molar ratios of $\mathrm{C}: \mathrm{N}$ decreased slightly with increasing $\mathrm{C}$ deposition, from 13.1 at 
Table 2. Rates of accumulation and concentration (as \% of dry weight) of particulate nitrogen (PN), particulate carbon (PC), and total recoverable phosphorus (TRP) in the settling tubes; and concentration of PN, PC, TRP, free sulphides ( $\mathrm{S}^{2-}$ ), loss on ignition (LOI) and estimated enrichment score (ES) in the benthic sediments. ES calculated from sulphide concentration follow ing Keeley et al. (2012a). Dash: not applicable

\begin{tabular}{|c|c|c|c|c|c|c|c|c|c|c|c|c|}
\hline \multirow[t]{2}{*}{ Site } & \multicolumn{6}{|c|}{ Settling tubes } & \multicolumn{6}{|c|}{ Benthic sediments } \\
\hline & $\begin{array}{c}\mathrm{PN} \\
(\mathrm{mmol} \\
\left.\mathrm{m}^{-2} \mathrm{~d}^{-1}\right)\end{array}$ & $\begin{array}{c}\mathrm{PC} \\
(\mathrm{mmol} \mathrm{m} \\
\left.\mathrm{m}^{-2} \mathrm{~d}^{-1}\right)\end{array}$ & $\begin{array}{c}\text { TRP } \\
\left(\mathrm{mmol}^{-2} \mathrm{~d}^{-1}\right)\end{array}$ & $\begin{array}{l}\mathrm{PN} \\
(\%)\end{array}$ & $\begin{array}{l}\mathrm{PC} \\
(\%)\end{array}$ & $\begin{array}{l}\text { TRP } \\
(\%)\end{array}$ & $\begin{array}{l}\text { PN } \\
(\%)\end{array}$ & $\begin{array}{l}\mathrm{PC} \\
(\%)\end{array}$ & $\begin{array}{l}\text { TRP } \\
(\%)\end{array}$ & $\begin{array}{c}\mathrm{S}^{2-} \\
(\mu \mathrm{M})\end{array}$ & $\begin{array}{l}\text { LOI } \\
(\%)\end{array}$ & ES \\
\hline H1 & 11.0 & 148 & 3.13 & 0.15 & 1.68 & 0.092 & 0.07 & 2.00 & 0.438 & 258 & 2.1 & 3.0 \\
\hline $\mathrm{H} 2$ & 23.7 & 303 & 8.53 & 0.19 & 2.05 & 0.148 & 0.16 & 2.03 & 0.654 & 456 & 1.9 & 3.5 \\
\hline H3 & 48.8 & 579 & 19.6 & 0.39 & 4.04 & 0.343 & 0.47 & 2.99 & 1.320 & 1535 & 3.2 & 4.6 \\
\hline $\mathrm{L}$ & - & - & - & - & - & - & 0.49 & 3.58 & 1.760 & 4491 & 6.0 & 6.3 \\
\hline
\end{tabular}

$\mathrm{H} 1,12.6$ at $\mathrm{H} 2$, to 12.1 at $\mathrm{H} 3$. The $\mathrm{C}: \mathrm{P}$ ratio also decreased (47.1, 35.7 and 30.4 respectively), as did the $\mathrm{N}: \mathrm{P}$ ratio $(3.6,2.8,2.5)$. The molar ratio of $\mathrm{C}$ deposition rate to mean oxygen flux (see Table 2) increased from 4.1 at $\mathrm{H} 1,5.7$ at $\mathrm{H} 2$, to 8.5 at H3. These trends show that material depositing at the sites most affected by the farm is enriched in $\mathrm{C}, \mathrm{N}$ and $\mathrm{P}$ relative to those least affected.

Some fraction of the material collected by the settlement tubes is likely to be resuspended material due to the high near-bed velocities. Consequently, the settlement tubes likely overestimate the net flux of material to the seabed. Findlay \& Watling (1997) accounted for resuspension by assuming that all ash (i.e. material remaining after ignition) present in their traps originated from the seabed, then used the ash content of the seabed sediments to adjust the $\mathrm{C}$ deposition rate. Their method indicates that $\sim 73 \%$ of the material collected in the settlement tube at H3 was resuspended. Ash content of wastes from salmon farms is $\sim 25 \%$ (Reid et al. 2009), so it is likely that a portion of the ash content in the settling tube was not resuspended material. However, assuming an ash content of $25 \%$ in salmon farm waste does not materially change the estimate of resuspension. A $73 \%$ resuspension rate at $\mathrm{H} 3$ seems reasonable, reducing the net $\mathrm{C}$ deposition rate to $\sim 155 \mathrm{mmol} \mathrm{C} \mathrm{m}^{-2} \mathrm{~d}^{-1}$, such that the molar ratio of net $\mathrm{C}$ deposition to oxygen flux would be $\sim 1.5$. This adjusted deposition rate is consistent with Hadfield et al. (2014), who estimated 10-20 g C m${ }^{-2} \mathrm{~d}^{-1}\left(120-240 \mathrm{mmol} \mathrm{C} \mathrm{m}^{-2} \mathrm{~d}^{-1}\right)$ in the vicinity of H3. However, applying the method of Findlay \& Watling (1997) to Sites H1 and H2, where $\mathrm{C}$ content in the settlement tubes is the same or lower than in the sediments, implies that there was either no net deposition (H2) or net erosion (H1). As is shown below (Section 3.5), benthic sediments at these sites were also enriched, so some $\mathrm{C}$ was being deposited. It is possible that there was remineralisa- tion of $\mathrm{C}$ in the settling tubes despite the use of formalin, in which case the $C$ content of the material in the tubes is under-reported. But water samples show high suspended sediments around the study site (unpubl. data), so it is likely that the settling tubes collected fine suspended inorganic material that does not settle on the seafloor due to the high current speeds.

\subsection{Benthic sediment properties}

Sediment analyses show consistent increases of all parameters (PN, PC, TRP and TS) across Sites H1 to H3. $N$, followed by $P$, were retained in greater proportions than $\mathrm{C}$ as loading increased. The highest concentrations of PN, PC, TRP and TS were observed at Site L. The second most enriched site, H3, was immediately next to the high-flow farm.

Molar ratios of $\mathrm{C}: \mathrm{N}$ in the benthic samples decreased much more rapidly with increasing enrichment than those collected from the settling tubes. The C:N ratio decreased from 33.3 at $\mathrm{H} 1$ to 7.4 at $\mathrm{H} 3$, closest to the farm. Again, from Sites H1 to H3, N:P molar ratios increased from 0.4 to 0.8 , while $\mathrm{C}: \mathrm{P}$ ratios decreased from 11.8 to 5.8. Molar ratios at Site L were similar to those at $\mathrm{H} 3(\mathrm{C}: \mathrm{N}$ ratio $=8.5$, $\mathrm{N}: \mathrm{P}=0.6$ and $\mathrm{C}: \mathrm{P}=5.2$ ).

There was a clear link between sediment chemistry and fluxes, with the benthic oxygen flux increasing with increasing enrichment (Fig. 7).

Based on sulphide concentrations, the enrichment score ES ranged from 3.0 to 4.6 for the high-flow sites and was 6.3 at Site L. Scores of 3.0 and 3.5 at H1 and H2 indicate moderate enrichment, with biological changes described by Keeley et al. (2012b) as 'notable abundance increase, decreased richness and diversity, with opportunistic species beginning to dominate'. The ES score of 4.6 at H3 indicates 

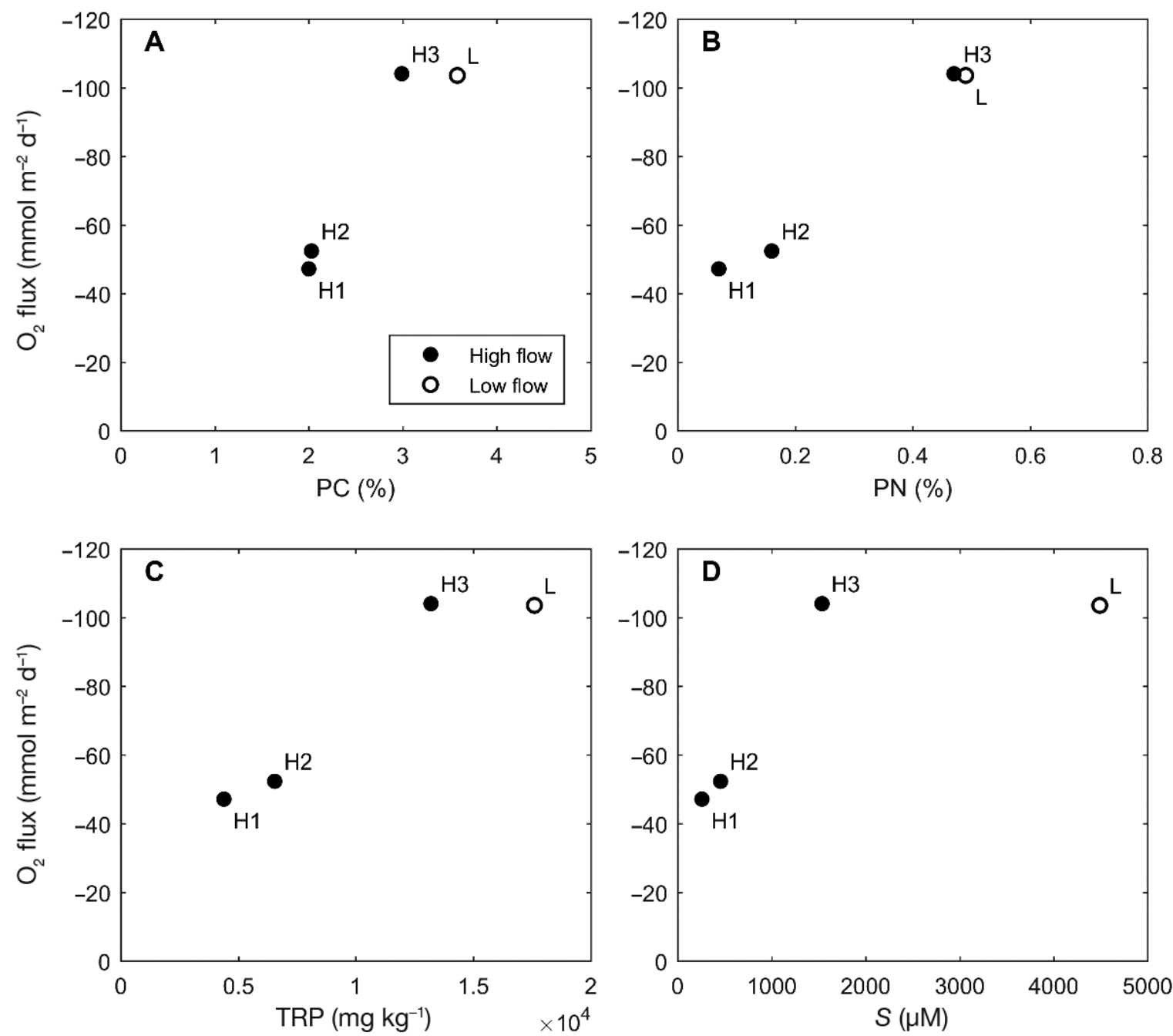

Fig. 7. Benthic oxygen flux plotted against (A) particulate C (PC), (B) particulate N (PN), (C) total reduceable P (TRP), and (D) sulphides (S) from benthic samples, for sites H1 (combined data from H1a and H1b), H2, H3, and L

major enrichment, with expected changes described as 'further reduced diversity, sub-peak abundances, opportunistic species begin to dominate, and major sediment chemistry changes'. At Site L, the ES score of 6.3 corresponds with conditions described as 'very low richness and diversity, reduced abundance of opportunistic species but not azoic, and very high (3 to 6 times reference conditions) \% organic matter'. The ES score also increased with increasing sediment $\mathrm{N}, \mathrm{P}$ and $\mathrm{C}$ concentrations.

At the high-flow sites, the benthic $\mathrm{C}: \mathrm{N}$ ratio decreased as $\mathrm{C}$ sedimentation rates (and oxygen flux) increased (Fig. 8), indicating a greater accumulation of nitrogen relative to carbon in the sediments (or a lower remineralisation rate of nitrogen relative to carbon). The N:P ratio shows the opposite (increasing) trend (Fig. 8D). While the carbon settlement rate was highest at $\mathrm{H} 3$, the total settlement in the tubes was nearly identical at Sites H2 and H3 ( 175 g total solids $\mathrm{m}^{-2} \mathrm{~d}^{-1}$ ) and $105 \mathrm{~g} \mathrm{~m}^{-2} \mathrm{~d}^{-1}$ at $\mathrm{H} 1$ (this excludes resuspension, which is likely to be similar at both sites). The higher nutrient content ( $\mathrm{N}, \mathrm{C}$ and $\mathrm{P})$ at $\mathrm{H3}$ relative to $\mathrm{H} 2$ and $\mathrm{H} 1$ (Table 2) suggests that heavier fractions that settle closer to the farm were more enriched compared to material that settled further from the farm. However, the C:N and N:P ratios in the sediment traps show the opposite trends to benthic samples - a small decrease in C:N as sedimentation rates and benthic oxygen fluxes increased (Fig. 8A) and a larger decrease in N:P (Fig. 8B). This difference between benthic sediments and that in settling tubes indicates that differences in the C:N:P ratios of the benthic sediments are not solely due to differences in the material settling in these locations. 

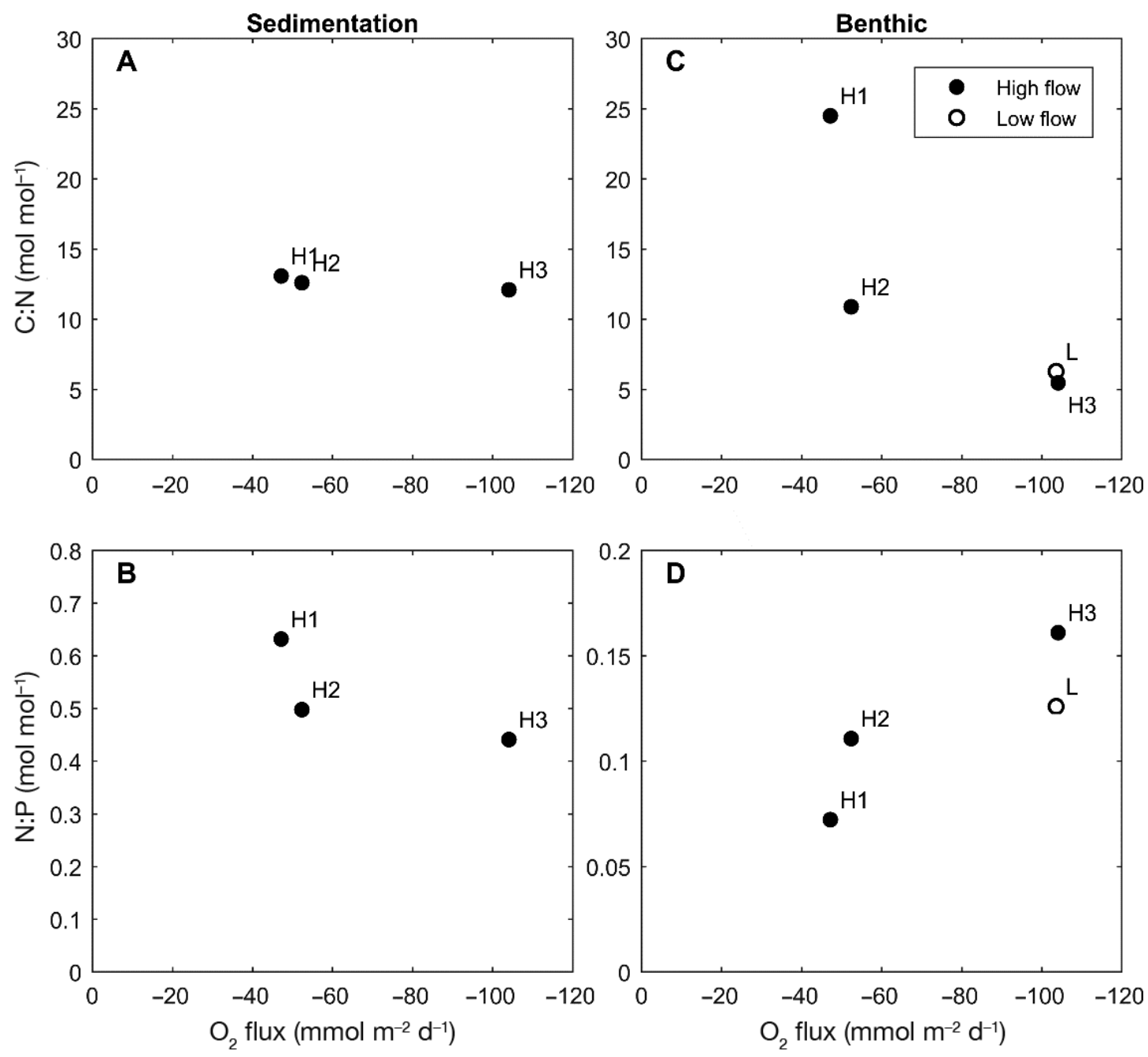

Fig. 8. (A) C:N and (B) N:P molecular ratios in sediments captured in sediment traps as functions of oxygen flux; and (C) C:N and (D) N:P molecular ratios in benthic samples for sites H1 (averaged data from sites H1a and H1b), H2, H3, and L

\section{DISCUSSION}

\subsection{Flux limitation and benthic impact}

The high-flow sites had similar hydrodynamic conditions, and the benthic oxygen flux increased in a near-linear fashion with sediment concentrations of PC, PN, TRP and sulphides. This suggests that where near-bed hydrodynamics are similar, oxygen fluxes relate well to sediment chemistry. However, the low-flow site (L) had similar benthic oxygen flux to Site H3, yet had higher sediment nutrient concentrations. Under low velocity and low turbulence conditions such as at Site L, oxygen transport to the sediments may be restricted. While DO flux to sediments is commonly modelled as a diffusive flux through a diffusive sublayer, turbulent sweeps and ejections are important mechanisms for transport to the sediment surface $\left(\mathrm{O}^{\prime}\right.$ Connor \& Hondzo 2008, Grant \& Marusic 2011). O'Connor \& Hondzo (2008) provide a model based on the concept of surface renewal by eddies that can be used to estimate the maximum (or potential) flux through the thin film next to the sediment surface that could be obtained under the hydrodynamic conditions observed at the study sites. The overall flux $J_{\max }$ is calculated as

$$
J_{\max }=-k\left(C_{\mathrm{w}}-C_{\mathrm{s}}\right)
$$

where $C_{\mathrm{w}}$ is the oxygen concentration in the water column above the near-bed thin film, and $C_{\mathrm{s}}$ the concentration at the sediment surface. The near-bed film has a thickness of $v / u_{*}$, where $v$ is the kinematic viscosity, and is generally $<1 \mathrm{~mm}$. The oxygen concen- 
tration at the height of the EC sensor can be used. The mass transfer coefficient $k$ is modelled as

$$
k=\frac{0.807}{\left(\frac{\alpha}{2}\right)^{1 / 3}} u_{*} S_{C}^{-2 / 3}
$$

The constant $\alpha$ is the ratio of the average time between bursting events and a timescale $v / u_{*}{ }^{2}$. The value $\alpha=238.5$ found experimentally by O'Connor \& Hondzo (2008) is used here. The Schmidt number $S_{C}=v / D$ (where $D$ is the oxygen diffusivity) has a value of $\sim 770$. In applying the above equations, transport is maximised if the oxygen concentration at the sediment surface is assumed to be $C_{s}=0$. It is unlikely that this is the case, as micro-profiler measurements of oxygen concentrations typically show that oxygen penetrates some distance into sediments (Jørgensen \& Des Marais 1990, Hondzo 1998), but assuming $C_{s}=0$ provides an upper bound to the potential flux estimate.

The equations above give predicted potential fluxes of -271 and $-302 \mathrm{mmol} \mathrm{m}^{-2} \mathrm{~d}^{-1}$ at Sites H1a and H1b, $-228 \mathrm{mmol} \mathrm{m}^{-2} \mathrm{~d}^{-1}$ at H2, $-273 \mathrm{mmol} \mathrm{m}^{-2} \mathrm{~d}^{-1}$ at H3, and $-123 \mathrm{mmol} \mathrm{m}^{-2} \mathrm{~d}^{-1}$ at Site L. The observed fluxes at the high-flow sites are all lower than these predicted potential fluxes, whereas the observed flux at Site L is close to the predicted potential flux (within $12 \%$ ). This suggests that although oxygen concentrations measured $0.15 \mathrm{~m}$ above the bed were near saturation (Table 1), the oxygen flux to the sediments at the low-flow site was near the maximum that could be obtained under those hydrodynamic conditions. This is supported by the significant correlation be- tween oxygen flux and oxygen concentration at Site L, consistent with Eq. (9), which predicts that the potential flux increases with oxygen concentration (Fig. 7B). Little dependence on velocity was seen at this site despite Eq. (9) predicting that increasing shear velocity (which scales with velocity) increases fluxes. This lack of dependency is likely due to the small range in velocities at this site.

Oxygen fluxes being at or near their maximum possible rate implies that there are likely to be hypoxic or anoxic conditions near or at the sediment surface, and sediments at the low-flow site were observed to be dark with a strong sulphurous odour. With an increasing reliance on alternative electron acceptors for decomposition of organic matter, sulphate reduction and other anaerobic metabolic processes dominate (Holmer \& Kristensen 1992), and significant changes in species composition and community structure will occur (Hargrave 2010). While observed benthic oxygen fluxes do not correlate linearly with sediment sulphides across high- and low-flow sites, the ratio of observed oxygen flux to the theoretical potential flux from Eq. (9) appears to relate well to sediment sulphides (Fig. 9A) and estimated ES score (Fig. 9B).

The ES was estimated here using only sediment sulphide concentrations. The true ES score is determined from several variables, many of which are biological indicators, but is strongly correlated to sulphide concentrations (Keeley et al. 2012a). Sediment biogeochemical properties and oxygen fluxes have been found to be more sensitive to organic enrichment than biological indicators (Hargrave et al. 1997, Giles 2008, Hargrave 2010), so the estimated ES score is expected
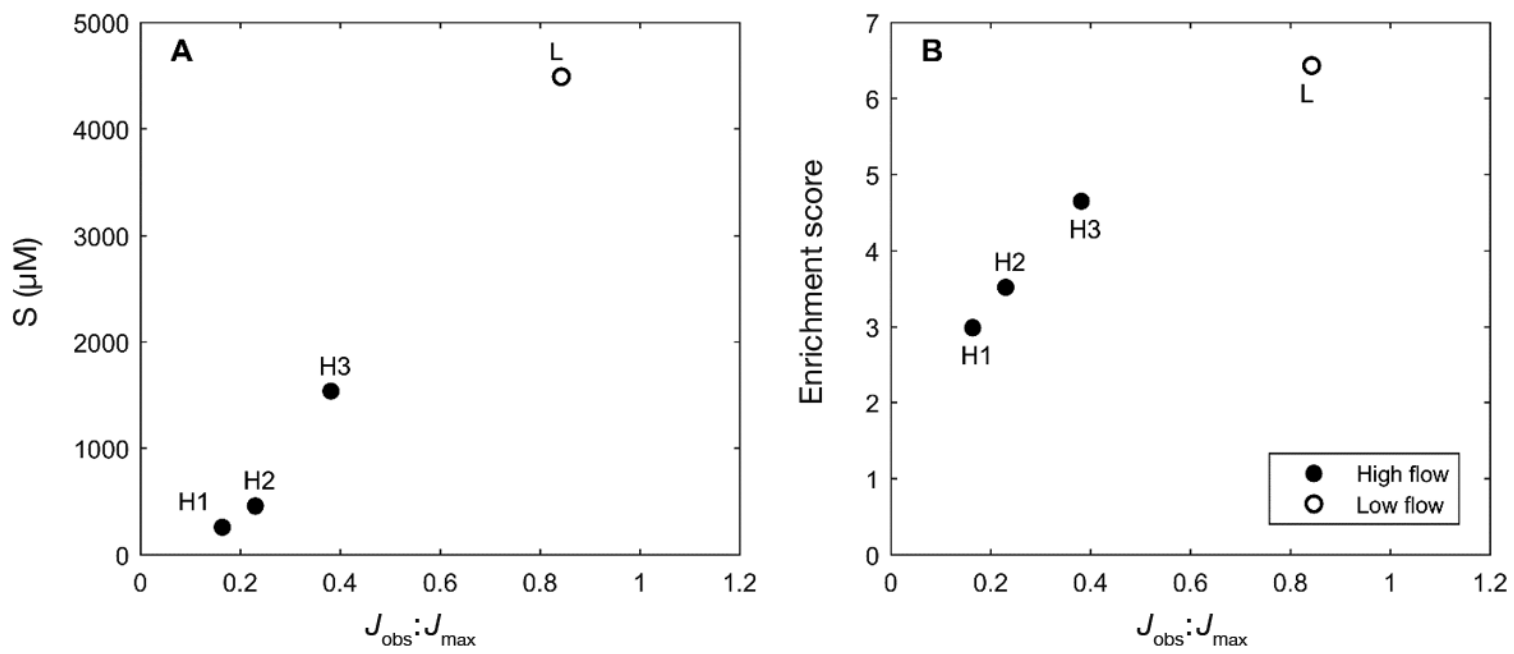

Fig. 9. (A) Sediment sulphide concentration (S) and (B) enrichment score plotted against ratio of observed benthic oxygen flux to theoretical maximum flux $\left(J_{\text {obs }}: J_{\max }\right)$, for sites H1, H2, H3, and L 
to be reasonably close to the true ES score. The estimated ES scores of 3.0, 3.5, 4.6 and 6.3 for $\mathrm{H} 1, \mathrm{H} 2, \mathrm{H} 3$ and L respectively are consistent with ES scores from observation and modelling of deposition footprints at Sites H1-H3 (Keeley et al. 2013), although may overestimate ES at Site L, where the range 5.5-6.0 was determined by Keeley et al. (2013), albeit for a different period of time. Note that if the coefficients for highflow sites are applied to the low-flow site, the ES score would be estimated as 5.6. Reference ES values (i.e. not impacted by salmon farm) for the Marlborough Sounds are $<2.5$ (Keeley et al. 2015), indicating some level of enrichment even at $\mathrm{H} 1$ and H2. The high estimated ES score at Site L, based on sulphide concentrations, is consistent with the inference that oxygen fluxes at this site were at or near maximum, and therefore hypoxic or anoxic conditions at the sediment surface were likely present with increased reliance on sulphate reduction (Holmer \& Kristensen 1992).

The sediment chemistry shows trends consistent with a reduction in the mineralisation rate of nitrogen with increased loading (Eyre \& Ferguson 2009). At the high-flow sites, the benthic $\mathrm{C}: \mathrm{N}$ ratio decreased (Fig. 8C), while N:P increased (Fig. 8D), as sedimentation rates (and oxygen flux) increased. Both trends are consistent with a reduction in the rate of $\mathrm{N}$ mineralisation. $\mathrm{N}$ can be released from sediments through nitrification and subsequent denitrification, but high loading conditions favour dissimilatory nitrate reduction to ammonia (Tiedje 1988, Nizzoli et al. 2006). Particulate phosphorus is retained until low $\mathrm{pH}$ conditions develop when it can be released back to the water column in soluble forms. C:N and N:P ratios in the sediment traps show the opposite trends to benthic samples - a small decrease in $\mathrm{C}: \mathrm{N}$ as sedimentation rates and benthic oxygen fluxes increased (Fig. 8A), and a larger decrease in N:P (Fig. 8B). Therefore, the increase in N:P in the benthic samples was not caused by differences in nutrient content of material depositing on the seabed, but it is consistent with less $\mathrm{N}$ being mineralized relative to $\mathrm{C}$ and $\mathrm{P}$. While some studies have reported reduction or loss of nitrification and denitrification under finfish farms (Kaspar et al. 1988, McCaig et al. 1999) and other forms of aquaculture (e.g. Christensen et al. 2003), the opposite has also been shown (Christensen et al. 2000, Lunstrum et al. 2018). Some of these differences are attributed to the use of acetylene in denitrification measurements, which inhibits nitrification (Christensen et al. 2000, Nizzoli et al. 2006).

Overall, the results of the present study confirm the widely held view that low-flow sites are less able to assimilate wastes than higher-flow sites (Black et al.
1996, Findlay \& Watling 1997) because of compounding factors: there is less dispersal of wastes resulting in a smaller footprint with higher deposition rates for equivalent loads (Keeley et al. 2013), less or no resuspension which also confines the footprint (Cromey et al. 2002), and the ability to transport oxygen to the sediments to mineralise or re-oxygenate reduced compounds is inhibited by low near-bed turbulence (O'Connor \& Hondzo 2008, Grant \& Marusic 2011).

\subsection{Comparison to other studies}

The EC technique has been used in a range of environments to measure oxygen uptake by sediments (e.g. Berg et al. 2003), transport through benthic and pelagic oxyclines (Kreling et al. 2014), and for studying ecosystem metabolism (e.g. Attard et al. 2015, Koopmans \& Berg 2015, Long et al. 2015, Rovelli et al. 2017). Benthic oxygen fluxes obtained from EC can show good agreement to other techniques such as sediment micro-profiling or benthic chambers, particularly over muddy sediments where little pore water flushing is expected (Berg et al. 2003, Attard et al. 2015, Donis et al. 2016). It is appropriate, therefore, to compare the flux measurements here to those in other studies of aquaculture sites. A wide range of benthic oxygen fluxes at finfish sites have been reported in the literature, some of which are summarised in Table 3. The range can be expected due to differences in farm size and biomass, and dispersal characteristics of sites (velocities and water depths). Some of the variability between reported values can also be due to seasonal effects (Christensen et al. 2000, Valdemarsen et al. 2012), changes in fish stocking rates over time or fallowing (Cathalot et al. 2012) or bioturbation (Nickell et al. 2003). However, some of the reported fluxes are considerably higher than observed here (e.g. Findlay \& Watling 1997, Nickell et al. 2003, Mulsow et al. 2006), which could be due to disturbance of cores (exposing labile organic matter or previously reduced inorganic compounds) or test conditions that created highly turbulent near-bed conditions increasing the potential oxygen flux rates. As described in Section 1, the EC method has several advantages over in situ chambers, incubation of cores or sediment micro-profiles that make it more likely to provide accurate estimates of oxygen fluxes occurring at the site under ambient hydrodynamic conditions.

Excluding the 3 highest fluxes values (Findlay \& Watling 1997, Nickell et al. 2003, Mulsow et al. 2006), the measured oxygen fluxes in this study (100- 


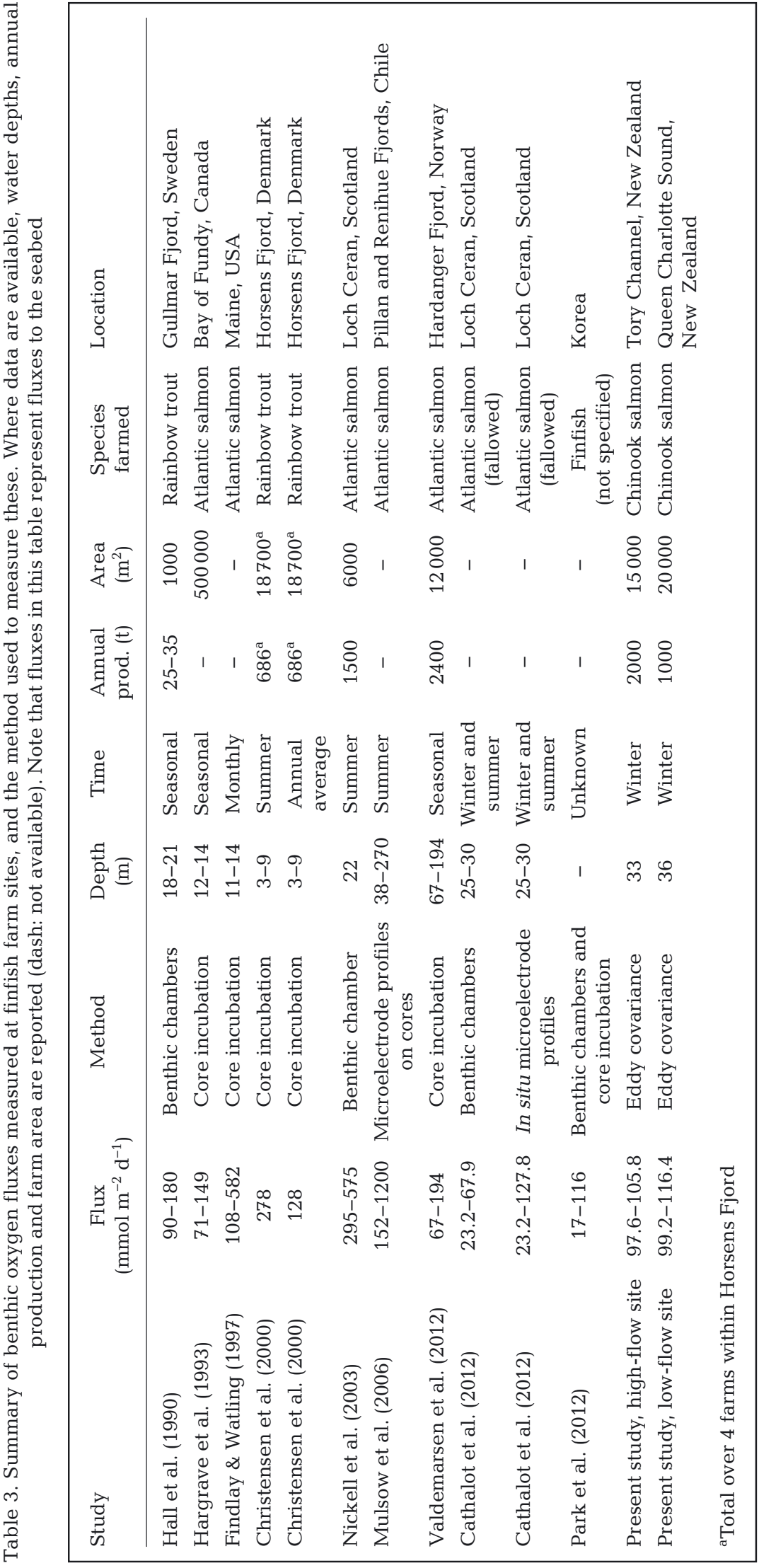

$110 \mathrm{mmol} \mathrm{m}^{-2} \mathrm{~d}^{-1}$ to the seabed) are within the range of reported fluxes at finfish sites. This study presents flux measurements over a short period of time, and fluxes might be expected to change as loading rates increase or decrease due to production cycles, and seasonal effects on respiration rates.

\subsection{Transient conditions and storage corrections}

The calculation of the true benthic oxygen flux from EC measurements can be offset by changes in the oxygen concentration over time (Holtappels et al. 2013, Rheuban et al. 2014). There are 2 effects to consider. Advection of water masses with different oxygen concentrations past the sensor generate a transient flux that was corrected for as described in the methods (Holtappels et al. 2013). However, changes in mean oxygen concentration can also be caused by time-varying benthic oxygen fluxes (Rheuban et al. 2014). This is common when there may be strong diurnal cycles in net ecosystem metabolism due to primary production. This can result in significant changes in storage of oxygen in the water column between the bed and the sensor. Corrections for this storage have been used elsewhere (Rheuban et al. 2014, Rovelli et al. 2017). The correction for storage assumes that rates of change in oxygen concentration are due solely to differences between the vertical flux of oxygen from the sediment surface and past the sensor (and hence storage in the water column between sensor and bed) and requires that oxygen concentrations are horizontally homogeneous. In the present study, it is likely that variable oxygen concentrations are due to horizontal advection of different water masses past the sensor (Fig. 3D), and there is no evidence of 
primary production with little light reaching the seabed. Therefore, the storage correction term was not applied.

The storage correction term (Rheuban et al. 2014) and the transient correction term (Holtappels et al. 2013) are both calculated from the rate of oxygen change, and this rate of change cannot easily be resolved into a transient and storage component. An attempt was made to use changes in temperature as well as thermal fluxes to determine when different water bodies were advected past the array. Thermal fluxes (averaging $0.5-1.0 \mathrm{~W} \mathrm{~m}^{-2}$ ) were calculated by applying the EC method to the temperature data measured by the RINKO-EC optode. If the temperature of different water bodies were different, then a vertical gradient would develop as this was advected past the sensor, resulting in changes in the vertical thermal flux. However, oxygen and temperature were poorly correlated, and changes in temperature or thermal flux provided no information that could be used to resolve changes in oxygen concentrations into advective or storage components. An approach that could possibly be explored to separate oxygen fluctuations into storage and transient components would be to use multiple oxygen sensors deployed in an array, with horizontal advection determined from lags between changes in oxygen concentration at sensors.

The absolute magnitude of the transient correction term (i.e. ignoring whether it was positive or negative) averaged at each site ranges between 8 and $40 \%$ of the mean flux, but as the sign of the correction changes, it nearly cancels out over the duration of the deployment and has little influence on the mean flux. If a storage correction term was applied, the mean fluxes would be altered by +6 to $-10 \%$ and the instantaneous flux values altered by between $25 \%$ (H1a) and 95\% (L). Both the oxygen transient term and the storage correction tend to average out over long deployments, although this can have important effects on the calculation of primary production and respiration rates from net ecosystem metabolism (Holtappels et al. 2013, Rheuban et al. 2014).

\subsection{Considerations for EC measurements at aquaculture sites}

This study shows that aquatic EC can successfully be used to measure benthic oxygen fluxes at aquaculture sites. There are conceptual and practical advantages of this approach compared to other techniques (e.g. spatial averaging, measuring under ambient conditions, easily deployed). However, there are also challenges. The equipment is expensive and delicate, requiring careful setup and deployment, and considerable post-processing of data is needed. Part of the reason for the slow uptake of the EC technique has been the availability of sensors that have sufficiently high sensitivity and fast response to measure small but rapid fluctuations due to turbulence, but that are also robust enough to survive field deployment. My experience suggests that optodebased oxygen sensors are more reliable in this environment. These are less prone to damage and fouling than galvanic sensors (Chipman et al. 2012, Berg et al. 2016) and generally have replaceable sensor heads or foils that are relatively inexpensive. While an attempt was made in the present study to compare a galvanic and optode sensor at site H1a, the galvanic sensor only provided potentially useful data for $2 \mathrm{~h}$ before sensitivity to oxygen fluctuations decreased due to a coating forming on the sensor.

Concerns have been raised about possible influences on fluxes due to flow interference by larger sensor units (Berg et al. 2016) if they are not downstream of the ADV sample volume. In the present study, more than half of the data was rejected because of unfavourable flow direction and likely flow interference. The velocity threshold to reject fluxes used here is slightly more permissive than the recommendation by Berg et al. (2016) that the RINKO-EC sensor be oriented such that flows are $\pm 60^{\circ}$, but has similar effect. The lower flux at H1a compared to H1b may be due to having 2 sensors (the optode and galvanic oxygen sensors) located near the sampling volume, with increased flow interference resulting in a reduction in the measured flux, although there was no significant difference in turbulence characteristics between H1a and $\mathrm{H} 1 \mathrm{~b}$. Smaller units are becoming available which may be less prone to issues from flow interference. Alternatively, 2 EC systems oriented in opposite directions could be deployed on a single frame or in close proximity so that more continuous flux measurements can be achieved. Further work is also required to account for changing oxygen concentrations due to advection of deoxygenated water from or under cages and separating this effect from changes in concentration due to differing benthic fluxes.

The footprint over which the EC method measures is a long, slender ellipsoid covering typically $10-$ $100 \mathrm{~m}^{2}$ (Berg et al. 2007). In deep water, the size of this footprint is determined by sensor height and seafloor roughness. In the present study, the footprint was $\sim 1.0 \mathrm{~m}$ wide and $50-85 \mathrm{~m}$ long. This footprint will also move as currents change direction. Where horizontal gradients in benthic enrichment 
are strong, such as close to cages, EC-derived fluxes may represent an average over this gradient, or be from a different location to where the instrument is located or sediment samples collected from. Mitigating this somewhat is that the peak contribution to the flux comes from relatively close to the sensor (2.4-4.4 $\mathrm{m}$ upstream in this study). In the present study, the orientation of the sensor meant that the measurement footprint was under the farm at $\mathrm{H} 3$, but from beside the farm at L (thus potentially missing the most impacted area).

A current limitation that the EC method has compared to chambers or core incubations is that fewer parameters can be measured due to the unavailability of suitable sensors. With chambers and cores, fluxes of other gases (e.g. $\mathrm{CO}_{2}$ and $\mathrm{N}_{2}$ ) or dissolved nutrients can also be measured, providing a more complete picture of benthic processes (e.g. Christensen et al. 2000, Eyre \& Ferguson 2009). To date, applications of aquatic EC have focused on oxygen, although the method has also been used for temperature, salinity and $\mathrm{H}_{2} \mathrm{~S}$ fluxes (Shirasawa et al. 1997, Crusius et al. 2008, Geyer et al. 2008, McGinnis et al. 2011). $\mathrm{H}_{2} \mathrm{~S}$ sensors may be useful for aquaculture studies, but because $\mathrm{H}_{2} \mathrm{~S}$ rapidly dissociates into $\mathrm{H}^{+}$ and $\mathrm{HS}^{-}$under the $\mathrm{pH}$ conditions seen at the present study site, EC measurements of $\mathrm{H}_{2} \mathrm{~S}$ flux are more likely to be successful in lower-pH waters.

The duration of deployments required to obtain reliable flux measurements in tidal flows requires some consideration (Kuwae et al. 2006, Attard et al. 2014, McGinnis et al. 2014, Attard et al. 2015). In the present study, photosynthesis could be ignored due to low light levels. If primary production at the seabed does occur, then flux measurements would need to cover both light and dark periods to resolve respiration rates from net ecosystem metabolism (Lorrai et al. 2010, Rheuban et al. 2014, Koopmans \& Berg 2015). However, fluxes may depend on flow speed (McGinnis et al. 2014). At low-light/non-photosynthetic tidal sites, measurements should therefore cover 1 tidal cycle at a minimum. Using data from longest deployment in this study (H2), mean fluxes converged to within $14 \%$ after one $12.5 \mathrm{~h}$ tidal cycle, and to $<10 \%$ after 2 tidal cycles. Some consideration may need to be given to spring-neap cycles, as higher velocities at spring tides may result in higher fluxes. However, a practical recommendation would be to measure over 2 tidal cycles (i.e. at least $24 \mathrm{~h}$, assuming semi-diurnal tides dominate) where possible. This duration would allow both a separation of primary production from respiration (if sufficient light reaches the seabed) and generally allow for a full tidal cycle under dark conditions whereby influence of velocity on respiration rates can be investigated.

The present study considers light-limited, winter conditions at the study sites. It is possible that in summer periods, benthic primary production may be stimulated by increased light, and warmer temperatures may affect respiration rates (Cathalot et al. 2012). Consequently, there may be seasonal changes in benthic processes at aquaculture sites, further modulated by changes in farm operating practices (feeding rates, stocking densities). Attard et al. (2014) found seasonal changes in benthic primary production, and that gross primary production can be stimulated at low light levels $\left(\sim 2 \mu \mathrm{mol}\right.$ quanta $\left.\mathrm{m}^{-2} \mathrm{~s}^{-1}\right)$, albeit in low-Arctic waters where the ecosystem is likely adapted to low light levels. Thus, while individual deployments should extend for at least $24 \mathrm{~h}$, further insight to benthic processes may be obtained through longitudinal studies using repeated deployments.

\section{CONCLUSIONS}

Oxygen flux measurements, in combination with measurements of benthic sediment chemistry, gave valuable insight into the effects of organic loading from salmon farms. As deposition rates increased, sediments became increasingly nutrient-enriched, and oxygen fluxes to the sediment increased. Evidence for decreasing nitrogen mineralisation efficiency (relative to carbon) with increasing load could be found in ratios of carbon, nitrogen and phosphorus in the sediments. As measured oxygen fluxes approached maximum potential flux rates predicted by surface renewal models, sediment samples showed accumulation of $\mathrm{C}, \mathrm{N}$ and $\mathrm{P}$ and increases in free sulphides. Oxygen fluxes were related to sediment nutrient concentrations, and under similar hydrodynamic conditions were related to benthic enrichment. Similar benthic oxygen fluxes were measured at sites adjacent to the high-flow and low-flow farms despite the low-flow site showing greater enrichment. However, scaling-observed oxygen fluxes by estimates of the potential flux obtainable under the ambient hydrodynamic conditions may provide a useful means of assessing benthic enrichment. Measurements of near-bed turbulence could be used to make predictions of sustainable benthic loadings for future aquaculture sites, or in combination with oxygen flux measurements, used to assess where a site sits along an enrichment gradient.

Optode-based EC sensors appear to be more suitable for use at finfish aquaculture sites than gal- 
vanic probes. The major advantages were their robustness and reliability, which allows long deployments, and that they appear to be more resistant to fouling or coating by material in the water column. Mean fluxes can be readily obtained, and deployments of at least $12-24 \mathrm{~h}$ are recommended at sites where little light reaches the seafloor. If light does reach the seafloor, then measurements need to span both dark/light and tidal cycles, and a minimum of $24 \mathrm{~h}$ may be required. As aquaculture sites are generally an oxygen sink, horizontally homogeneous oxygen concentrations cannot be assumed, and the effect of transient oxygen concentrations on flux measurements needs to be considered over short timescales.

Acknowledgements. Thanks to Mike Page for assistance with the fieldwork, Niall Broekhuizen and Craig Depree for discussion and feedback on drafts of this manuscript, Peter Berg for discussions regarding the eddy covariance technique, Cynthia Bluteau for sharing Matlab scripts for calculating turbulent kinetic energy (TKE) dissipation rates, and New Zealand King Salmon for allowing deployment of equipment close to operating salmon farms. Three anonymous reviewers provided valuable and insightful feedback. This study was funded by the New Zealand Ministry of Business, Innovation and Employment through the NIWA Core Funded Environmental Effects of Aquaculture Programme.

\section{LITERATURE CITED}

Attard KM, Glud RN, McGinnis DF, Rysgaard S (2014) Seasonal rates of benthic primary production in a Greenland fjord measured by aquatic eddy correlation. Limnol Oceanogr 59:1555-1569

Attard KM, Stahl H, Kamenos NA, Turner G, Burdett HL, Glud RN (2015) Benthic oxygen exchange in a live coralline algal bed and an adjacent sandy habitat: an eddy covariance study. Mar Ecol Prog Ser 535:99-115

* Berg P, Roy H, Janssen F, Meyer V, Jorgensen BB, Huettel M, de Beer D (2003) Oxygen uptake by aquatic sediments measured with a novel non-invasive eddy-correlation technique. Mar Ecol Prog Ser 261:75-83

Berg P, Roy H, Wiberg PL (2007) Eddy correlation flux measurements: the sediment surface area that contributes to the flux. Limnol Oceanogr 52:1672-1684

Berg P, Glud RN, Hume A, Stahl H, Oguri K, Meyer V (2009) Eddy correlation measurements of oxygen uptake in deep ocean sediments. Limnol Oceanogr Methods 7:576-584

Berg P, Koopmans DJ, Huettel M, Li H, Mori K, Wüest A (2016) A new robust oxygen-temperature sensor for aquatic eddy covariance measurements. Limnol Oceanogr Methods 14: 151-167

Black KD, Kiemer MCB, Ezzi IA (1996) The relationships between hydrodynamics, the concentration of hydrogen sulphide produced by polluted sediments and fish health at several marine cage farms in Scotland and Ireland. J Appl Ichthyol 12:15-20

Bluteau CE, Jones NL, Ivey GN (2011) Estimating turbulent kinetic energy dissipation using the inertial subrange method in environmental flows. Limnol Oceanogr Methods 9:302-321

*Bown JR, Gowen RJ, McLusky DS (1987) The effect of salmon farming on the benthos of a Scottish sea loch. J Exp Mar Biol Ecol 109:39-51

Cathalot C, Lansard B, Hall POJ, Tengberg A and others (2012) Spatial and temporal variability of benthic respiration in a Scottish sea loch impacted by fish farming: a combination of in situ techniques. Aquat Geochem 18: 515-541

Chipman L, Huettel M, Berg P, Meyer V, Klimant I, Glud R, Wenzhoefer F (2012) Oxygen optodes as fast sensors for eddy correlation measurements in aquatic systems. Limnol Oceanogr Methods 10:304-316

* Christensen PB, Rysgaard S, Sloth NP, Dalsgaard T, Schwærter S (2000) Sediment mineralization, nutrient fluxes, denitrification and dissimilatory nitrate reduction to ammonium in an estuarine fjord with sea cage trout farms. Aquat Microb Ecol 21:73-84

Christensen PB, Glud RN, Dalsgaard T, Gillespie P (2003) Impacts of longline mussel farming on oxygen and nitrogen dynamics and biological communities of coastal sediments. Aquaculture 218:567-588

* Cromey CJ, Nickell TD, Black KD (2002) DEPOMOD modelling the deposition and biological effects of waste solids from marine cage farms. Aquaculture 214:211-239

* Crusius J, Berg P, Koopmans DJ, Erban L (2008) Eddy correlation measurements of submarine groundwater discharge. Mar Chem 109:77-85

* Dade WB (1993) Near-bed turbulence and hydrodynamic control of diffusional mass transfer at the sea floor. Limnol Oceanogr 38:52-69

* Donis D, McGinnis DF, Holtappels M, Felden J, Wenzhoefer F (2016) Assessing benthic oxygen fluxes in oligotrophic deep sea sediments (HAUSGARTEN observatory). Deep Sea Res I 111:1-10

Eyre BD, Ferguson AJP (2009) Denitrification efficiency for defining critical loads of carbon in shallow coastal ecosystems. Hydrobiologia 629:137-146

* Findlay RH, Watling L (1997) Prediction of benthic impact for salmon net-pens based on the balance of benthic oxygen supply and demand. Mar Ecol Prog Ser 155:147-157

*Findlay RH, Watling L, Mayer LM (1995) Environmental impact of salmon net-pen culture on marine benthic communities in Maine: a case study. Estuaries 18:145-179

* Geyer WR, Scully ME, Ralston DK (2008) Quantifying vertical mixing in estuaries. Environ Fluid Mech 8:495-509

Giles H (2008) Using Bayesian networks to examine consistent trends in fish farm benthic impact studies. Aquaculture 274:181-195

Glud RN (2008) Oxygen dynamics of marine sediments. Mar Biol Res 4:243-289

*Goring DG, Nikora VI (2002) Despiking acoustic Doppler velocimeter data. J Hydrol Eng 128:117-126

* Grant SB, Marusic I (2011) Crossing turbulent boundaries: interfacial flux in environmental flows. Environ Sci Technol 45:7107-7113

Hadfield M, Broekhuizen N, Plew D (2014) A biophysical model for the Marlborough Sounds. Part 1: Queen Charlotte Sound and Tory Channel. Rep No. CHC2014-116. NIWA, Christchurch

*Hall POJ, Anderson LG, Holby O, Kollberg S, Samuelsson MO (1990) Chemical fluxes and mass balances in a marine fish cage farm. I. Carbon. Mar Ecol Prog Ser 61:61-73 Hargrave BT (2010) Empirical relationships describing ben- 
thic impacts of salmon aquaculture. Aquacult Environ Interact 1:33-46

Hargrave BT, Duplisea DE, Pfeiffer E, Wildish DJ (1993) Seasonal changes in benthic fluxes of dissolved oxygen and ammonium associated with marine cultured Atlantic salmon. Mar Ecol Prog Ser 96:249-257

Hargrave BT, Phillips GA, Doucette LI, White MJ, Milligan TG, Wildish DJ, Cranston RE (1997) Assessing benthic impacts of organic enrichment from marine aquaculture. In: Evans RD, Wisniewski J, Wisniewski JR (eds) The interactions between sediments and water. Proc 7 th Int Symp, Baveno, Italy, 22-25 Sep 1996. Springer, Dordrecht, p 641-650

*Holmer M, Kristensen E (1992) Impact of marine fish cage farming on metabolism and sulfate reduction of underlying sediments. Mar Ecol Prog Ser 80:191-201

Holtappels M, Glud RN, Donis D, Liu B, Hume A, Wenzhöfer F, Kuypers MMM (2013) Effects of transient bottom water currents and oxygen concentrations on benthic exchange rates as assessed by eddy correlation measurements. J Geophys Res Oceans 118:1157-1169

* Hondzo M (1998) Dissolved oxygen transfer at the sedimentwater interface in a turbulent flow. Water Resour Res 34: 3525-3533

JFE Advantech (2017) Rinko EC user's manual. JFE Advantech, Nishinomiya

* Jørgensen BB, Des Marais DJ (1990) The diffusive boundary layer of sediments: oxygen microgradients over a microbial mat. Limnol Oceanogr 35:1343-1355

Kaspar HF, Hall GH, Holland AJ (1988) Effects of sea cage salmon farming on sediment nitrification and dissimilatory nitrate reductions. Aquaculture 70:333-344

Keeley NB, Forrest BM, Crawford C, Macleod CK (2012a) Exploiting salmon farm benthic enrichment gradients to evaluate the regional performance of biotic indices and environmental indicators. Ecol Indic 23:453-466

Keeley NB, Macleod CK, Forrest BM (2012b) Combining best professional judgement and quantile regression splines to improve characterisation of macrofaunal responses to enrichment. Ecol Indic 12:154-166

*Keeley NB, Cromey CJ, Goodwin EO, Gibbs MT, Macleod CM (2013) Predictive depositional modelling (DEPOMOD) of the interactive effect of current flow and resuspension on ecological impacts beneath salmon farms. Aquacult Environ Interact 3:275-291

K Keeley NB, Forrest BM, Macleod CK (2015) Benthic recovery and re-impact responses from salmon farm enrichment: implications for farm management. Aquaculture 435:412-423

Koopmans DJ, Berg P (2015) Stream oxygen flux and metabolism determined with the open water and aquatic eddy covariance techniques. Limnol Oceanogr 60:1344-1355

Kreling J, Bravidor J, McGinnis DF, Koschorreck M, Lorke A (2014) Physical controls of oxygen fluxes at pelagic and benthic oxyclines in a lake. Limnol Oceanogr 59: 1637-1650

Kuwae T, Kamio K, Inoue T, Miyoshi E, Uchiyama Y (2006) Oxygen exchange flux between sediment and water in an intertidal sandflat, measured in situ by the eddy-correlation method. Mar Ecol Prog Ser 307:59-68

Long MH, Berg P, Falter JL (2015) Seagrass metabolism across a productivity gradient using the eddy covariance, Eulerian control volume, and biomass addition techniques. J Geophys Res Oceans 120:3624-3639

* Lorke A, Müller B, Maerki M, Wüest A (2003) Breathing sediments: the control of diffusive transport across the sediment - water interface by periodic boundary-layer turbulence. Limnol Oceanogr 48:2077-2085

* Lorke A, McGinnis DF, Maeck A (2013) Eddy-correlation measurements of benthic fluxes under complex flow conditions: effects of coordinate transformations and averaging time scales. Limnol Oceanogr Methods 11:425-437

* Lorrai C, McGinnis DF, Berg P, Brand A, Wüest A (2010) Application of oxygen eddy correlation in aquatic systems. J Atmos Ocean Technol 27:1533-1546

* Lunstrum A, McGlathery K, Smyth A (2018) Oyster (Crassostrea virginica) aquaculture shifts sediment nitrogen processes toward mineralization over denitrification. Estuar Coast 41:1130-1146

* McCaig AE, Phillips CJ, Stephen JR, Kowalchuk GA and others (1999) Nitrogen cycling and community structure of proteobacterial beta-subgroup ammonia-oxidizing bacteria within polluted marine fish farm sediments. Appl Environ Microbiol 65:213-220

* McGinnis DF, Berg P, Brand A, Lorrai C, Edmonds TJ, Wüest A (2008) Measurements of eddy correlation oxygen fluxes in shallow freshwaters: towards routine applications and analysis. Geophys Res Lett 35:L04403

*McGinnis DF, Cherednichenko S, Sommer S, Berg P and others (2011) Simple, robust eddy correlation amplifier for aquatic dissolved oxygen and hydrogen sulfide flux measurements. Limnol Oceanogr Methods 9:340-347

McGinnis DF, Sommer S, Lorke A, Glud RN, Linke P (2014) Quantifying tidally driven benthic oxygen exchange across permeable sediments: an aquatic eddy correlation study. J Geophys Res Oceans 119:6918-6932

* Mulsow S, Krieger Y, Kennedy R (2006) Sediment profile imaging (SPI) and micro-electrode technologies in impact assessment studies: example from two fjords in Southern Chile used for fish farming. J Mar Syst 62:152-163

Nickell LA, Black KD, Hughes DJ, Overnell J and others (2003) Bioturbation, sediment fluxes and benthic community structure around a salmon cage farm in Loch Creran, Scotland. J Exp Mar Biol Ecol 285-286:221-233

* Nizzoli D, Welsh DT, Fano EA, Viaroli P (2006) Impact of clam and mussel farming on benthic metabolism and nitrogen cycling, with emphasis on nitrate reduction pathways. Mar Ecol Prog Ser 315:151-165

* O'Connor BL, Hondzo M (2008) Dissolved oxygen transfer to sediments by sweep and eject motions in aquatic environments. Limnol Oceanogr 53:566-578

Park JH, Cho YS, Lee WC, Hong SJ, Kim HC, Kim JB (2012) Comparison of material flux at the sediment-water interface in marine finfish and abalone cage farms, southern coast of Korea: in-situ and laboratory incubation examination. J Korean Soc Mar Environ Saf 18:536-544

* Pischedda L, Poggiale JC, Cuny P, Gilbert F (2008) Imaging oxygen distribution in marine sediments. The importance of bioturbation and sediment heterogeneity. Acta Biotheor 56:123-135

*Plew DR, Stevens CL (2013) Numerical modelling of the effect of turbines on currents in a tidal channel - Tory Channel, New Zealand. Renew Energy 57:269-282

* Reid GK, Liutkus M, Robinson SMC, Chopin TR and others (2009) A review of the biophysical properties of salmonid faeces: implications for aquaculture waste dispersal models and integrated multi-trophic aquaculture. Aquacult Res 40:257-273

* Rheuban JE, Berg P, McGlathery KJ (2014) Multiple timescale processes drive ecosystem metabolism in eelgrass 
(Zostera marina) meadows. Mar Ecol Prog Ser 507:1-13 Rovelli L, Attard KM, Binley A, Heppell CM, Stahl H, Trimmer M, Glud RN (2017) Reach-scale river metabolism across contrasting sub-catchment geologies: effect of light and hydrology. Limnol Oceanogr 62:S381-S399

Røy H, Hüttel M, Jørgensen BB (2002) The role of smallscale sediment topography for oxygen flux across the diffusive boundary layer. Limnol Oceanogr 47:837-847

Shirasawa K, Grant Ingram R, Hudier EJJ (1997) Oceanic heat fluxes under thin sea ice in Saroma-ko Lagoon, Hokkaido, Japan. J Mar Syst 11:9-19

Sulpis O, Mucci A, Boudreau BP, Barry MA, Johnson BD (2019) Controlling the diffusive boundary layer thickness above the sediment-water interface in a thermostated rotating-disk reactor. Limnol Oceanogr Methods 17: 241-253

Svensson J, Leonardson L (1996) Effects of bioturbation by

Editorial responsibility: Marianne Holmer, Odense, Denmark tube-dwelling chironomid larvae on oxygen uptake and denitrification in eutrophic lake sediments. Freshw Biol 35:289-300

* Sweetman AK, Norling K, Gunderstad C, Haugland BT, Dale $\mathrm{T}$ (2014) Benthic ecosystem functioning beneath fish farms in different hydrodynamic environments. Limnol Oceanogr 59:1139-1151

Tiedje JM (1988) Ecology of denitrification and dissimilatory nitrate reduction to ammonium. In: Zejnder AJB (ed) Biology of anaerobic microorganisms. John Wiley \& Sons, New York, NY, p 179-244

*Valdemarsen T, Bannister RJ, Hansen PK, Holmer M, Ervik A (2012) Biogeochemical malfunctioning in sediments beneath a deep-water fish farm. Environ Pollut 170:15-25

*Wilczak J, Oncley S, Stage S (2001) Sonic anemometer tilt correction algorithms. Boundary-Layer Meteorol 99: $127-150$

Submitted: November 19, 2018; Accepted: May 11, 2019

Proofs received from author(s): July 3, 2019 